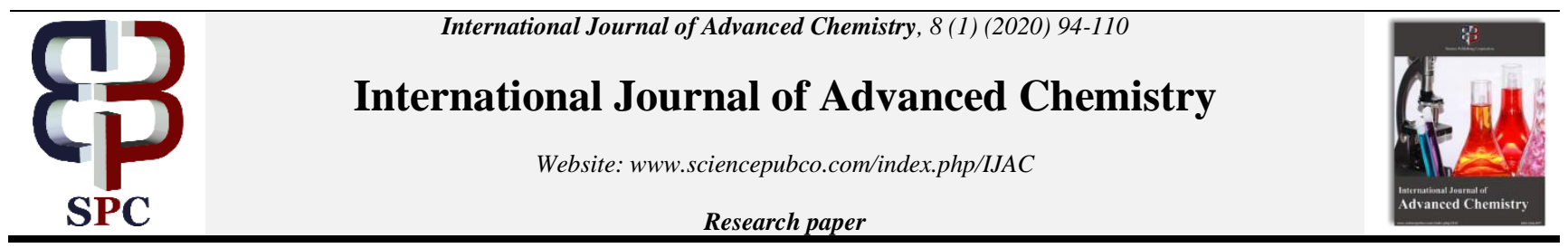

\title{
Hereditary immunity in cancer
}

\author{
Alireza Heidari ${ }^{1,2}$ *, Katrina Schmitt ${ }^{1}$, Maria Henderson ${ }^{1}$, Elizabeth Besana ${ }^{1}$ \\ ${ }^{1}$ Faculty of Chemistry, California South University, 14731 Comet St. Irvine, CA 92604, USA \\ ${ }^{2}$ American International Standards Institute, Irvine, CA 3800, USA \\ *Corresponding author E-mail: Scholar.Researcher.Scientist@gmail.com
}

\begin{abstract}
Cancer is one of the malignant diseases and millions of people worldwide die from cancer annually. Breast cancer diagnosis requires the analysis of images and attributes as well as collecting many clinical and mammography variables. In diagnosis of breast cancer, it is important to determine whether a tumor is benign or malignant. The information about breast cancer risk prediction along with the type of tumor are crucial for patients and effective medical decision making. An ideal diagnostic system could effectively distinguish between benign and malignant cells; however, such a system has not been created yet. In this study, a model is developed to improve the prediction probability of breast cancer. It is necessary to have such a prediction model as the survival probability of breast cancer is high when patients are diagnosed at early stages.
\end{abstract}

Keywords: Hereditary; Immunity; Cancer.

\section{Introduction}

The breast cancer is the leading cause for cancer-related deaths in women. Due to modern lifestyle, number of diagnosed patients with breast cancer in the developed countries are on the top of the list around the world [1-27]. The most common type of breast cancer is ductal carcinoma, which begins in the cells of the ducts. Breast cancer can also begin in the cells of the lobules and in other tissues in the breast [28-49]. In the U.S., breast cancer is the second most common cancer in women after skin cancer. It can occur in both men and women, but it is rare in men. Each year there are about 100 times more new cases of breast cancer in women than in men. In this project we applied several machine learning techniques on the Wisconsin Diagnostic Breast Cancer data set to classify the cancer based on the feature extracted from images as benign or malignant [50-73].

In the current age, pancreatic cancer is one of the worst forms of cancer. The complications of pancreatic include five types of pancreatitis, benign tumors, malignant tumors, benign cysts and malignant cysts. This cancer has a few clinical symptoms than other cancers. Also, if not treated in a timely manner, it also causes other organs of the body and the patient chance of survival is greatly reduced. One of the ways to detect this disease is to use CT scan images. But the appearance of pancreatic complications is very different in a similar category, and their tissue is very similar to healthy abdominal tissues. For this reason, it's very difficult to identify the range of complications. In this study, the data contained 151CT scan images. These images are divided into five classes of pancreatitis, malignant tumors, benign tumors, malignant cysts, benign cysts and a healthy class. The pancreatic complications are varied and different, if the diagnostic system is based on simple experts; the possibility of achieving high detection accuracy is not possible. According to the results of this study, lonely no classification can detect all diseases and combining these methods is the best option. Therefore, in this study we have achieved high accuracy in prediction (690.69) by combining the perception, convolution and SVM neural networks.

\section{Manifestations of hereditary immunity in cancer}

\subsection{In first discovery of hereditary immunity to cancer}

Polyurethane are biocompatible compounds with variety applications in the biomedical fields mostly as drug delivery vehicles. Their various applications are due to their Maneuverable structure with different blocks of diols and isocyanides. In the new presented work, magnetic polyurethane was used as drug carrier which formed of the reaction of Poly-caprolacton and isophoren diisocyanate and finally cyclodextrin as the cross linker. Characterization of the final polymer and certainty of its formation was done through different analytical methods such as FT-IR, TGA, XRD, SEM, TEM and VSM. On the other hand, the percentage of the magnetic nanoparticles in the polymer matrices was tracked using thermal gravimetery analysis. This Nano drug carrier was used for in vitro delivering pharmaceutical agent of doxorubicin. The amount of drug loading and percentage and manner of the drug release were investigated using concentration profile. Cytotoxicity of Nano drug carrier was evaluated using calorimetric method called methylthiazoletetrazolium (MTT) assay on the MCF-7 cell lines and according to the results presented system is very profitable and proper one for delivering Doxorubicin anti-cancer drug [7493]. 
Melittin (MEL) is a kind of catalytic peptide that isolated from bee venom. Catalytic peptides are promising drugs for cancer treatment because cancer cells are less likely to develop resistance to a membrane-perturbing agent. However, their nonspecific cytotoxicity has limited their therapeutic applications. In this study, we use citric acid stabilized $\mathrm{Fe} 3 \mathrm{O} 4$ magnetic nanoparticles (CA-MNP) as potential magnetic carriers for target delivery of melittin to tumor sites. The morphology and surface functionalization of these magnetic Nano carriers were studied by field emission scanning electron microscopy (FESEM) and Fourier transform infrared. The loading and release profile of MEL were studied by UV spectrophotometry. The results indicate that these magnetic Nano carriers have the high drug loading efficiency and the $\mathrm{pH}$-dependent release behavior. The in vitro cytotoxicity of the MEL-loaded CA-MNP on the MCF-7 breast cancer cell line is similar to that of free MEL in solution at equivalent doses [94-104].

The interest in exploring more effective methods for cancer treatment has increased widely in recent years. In clinical studies it is difficult to determine the temperature distribution in both normal tissue and in tumor during hyperthermia treatment since temperature can be measured in limited number of positions in tissue or tumor. Simulation studies can play crucial role in physician's perception of the temperature distribution in tissue. Hyperthermia treatment is facing some unsolved problems such as the appropriate dosage of magnetic Nano particles required to achieve the optimum temperature which results in apoptosis in tumor cells. In this study, a 2D computational model is created in COMSOL Metaphysics in order to analyze temperature distribution in both normal tissue and tumor during hyperthermia treatment using various dosages of magnetic Nano particles. Temperature distribution is achieved by considering various layers from wave source through to the tumor and also by taking into account the amount of heat generated through the Brownian rotation and the Neel relaxation. Simulations of a spherical tumor located in ellipse tissue were designed. A systematical variation in dosage has been performed. Temperature distribution and maximum temperature in steady state and effect of the dosage of Nano particles [105-117].

\subsection{Over observations of cancer prevalence}

In this study, cobalt Ferrite nanoparticles with inverse spinel structures were obtained using co-precipitation of cobalt and iron nitrates. Ammonia 15\% was used as an alkaline agent for $\mathrm{pH}$ adjustment. Besides, we used oleic acid to coat the cobalt ferrite nanoparticles. XRD analysis showed that the samples included spinel ferrite structure. According to the results of SEM the distribution of the particles was homogeneous and the particles were uniform, and pseudo-spherical in shape. The magnetic properties of the material were analyzed by the VSM that showed the relationship between super-paramagnetic properties of the material and particle size. In this research, for the first time, anti-cancer effects of cobalt ferrite nanoparticles on K562 cell line as an experimental model of acute myeloid leukemia (CML) were examined. Because this compound has the potential to induce differentiation and apoptosis, it can be used in conjunction with other pharmaceutical compounds as a promising candidate for the treatment of blood cancer patients [118-143].

Cancer, as a leading contributor to the global disease burden is characterized by the uncontrolled growth of cells in the body, which makes it one of the most difficult and complex diseases to treat. Dietary sources of natural products including fruits and vegetables have been reported to be associated with reduced risk of a variety of tumors and to have anti-cancer benefits, apart from being a good source of nutrients. Thus, among major groups of anti-cancer drugs, plant extracts have received considerable attention to discover promising cancer therapeutic agents from natural sources. Great interest is currently centered on the biologic activities of quercetin a polyphenol belonging to the class of flavonoids, natural products well known for their beneficial effects on health, long before their biochemical characterization. onion skin waste is rich in bioactive compounds such as phenolic and flavonoids. In this direction, Quercetin, a natural compound abundantly present in Onion skin has great therapeutic potential in the prevention and treatment of cancer. This review focuses on anti-cancer potential of Quercetin with current advancements for its implementation in treatment of cancers [144-156].

\subsection{Ethnic and racial differences in cancer prevalence}

Boron neutron capture therapy (BNCT) is efficient therapeutic methods in cancer treatment based on nuclear capture and fission reactions. In this method, use of the best boron-containing agents for boron therapy and boron delivery agent for delivery of them to the infectious site are key points in therapy efficiency. Our research indicated that calcium fructoborate was the best compound as a boron-containing agent for boron therapy. Furthermore, studies have demonstrated that liposomes can effectively and selectively deliver large quantities of boron to tumors and that the compounds delivered by liposomes have a longer tumor retention time. Indeed, liposomal encapsulation of calcium fructoborate has been extensively evaluated as Nano vehicles for the delivery of boron compounds for BNCT. In this study, we deeply investigate molecular composition of the calcium fructoborate used as a carrier supplement for cancer therapy, by using FT-IR, XRD, TG, DSC and Raman spectroscopic analysis. The experimental measurements agree very well with the molecular formula $\mathrm{Ca}[(\mathrm{C} 6 \mathrm{H} 10 \mathrm{O} 6) 2 \mathrm{~B}] 24 \mathrm{H} 2 \mathrm{O}[157-173]$.

Children are one of the easiest affected group from environmental deterioration and detrimental factors, Due to their biological and behavioral differences. And childhood cancer has considered as one of the most common cause of death in children in developing countries. Exposure to some environmental factors during childhood can increase the risk of cancer in the offspring. This study aimed to evaluated the role of living in the pollutant regions and exposure to cigarette or hookah smoke on the incidence of cancer in children. This case control study was considered 22 cases and 100 controls, under 10 years, who was born and lived in pollutant regions of the world in 20142015. Regarding to the important risk factors: familial background of underlying diseases or cancer. However, in this ages, Familial background of cancer is considered as the most crucial risk factor of the incidence of cancer in children $(\mathrm{P}=0.000, \mathrm{OR}=7.639, \mathrm{CI} 95 \% 4.230$ 13.794). Moreover, the second most significant item is live in regions with polluted air ( $\mathrm{P}=0.019, \mathrm{OR}=4.222$, CI 95\% 1.172-15.211) [174189].

\subsection{Population differences in cancer prevalence}

Breast cancer is the uncontrolled growth of abnormal cells in the breast area and it is one of the widespread causes of mortality in today's world. So that 8000 people are diagnosed with breast cancer of a year in the world. The exact and precise diagnosis is considered as the vital point in the process of treatment. Among the various methods of screening, thermography is a non-invasive and safe method to detect breast cancer. In this work, a classification algorithm of thermograms with the purpose of detection of breast cancer from gray level cooccurrence matrix based features texture has been proposed. For this purpose, 52 images from the breast of healthy and unhealthy people from the data were collected. The preprocessing and segmentation of data was performed in gray level for the creation of temperature matrix. Finally, the gray level co-occurrence matrix based features was extracted from the matrix and the collection of features using Manhattan technique was the input for weighted K-nearest neighbor classifier. The result of Accuracy was 85.6, Sensitivity was 91.7 and Specificity Index was 81.2 selected as the optimal structure compared to other methods that have been proposed so far [190-203]. 
Cancer is the third leading cause of death in the world, as well as breast cancer is the second most common cause of death among women in the world. According to calculations by the National Cancer Institute of the United States, one person of every eight women will be diagnosed with breast cancer. Unfortunately, the age of cancer in the world is a decade younger than other developed countries. Therefore, early diagnosis of this disease is essential in the healing process. With detect and remove cancerous tumors in the early stages before spreading to neighboring areas, cancer threats be stopped. Among the various methods of screening, thermography is a non-invasive and safe method to detect breast cancer. In research, at first paid to the automatically way that in this regard, Kenny edge and Hough transform have been enjoying and then a thermography classification algorithm to detect breast cancer based on certain characteristics extraction of the tissue in gray level co-occurrence matrix is provided. For this purpose, 68 healthy and unhealthy images of the breast are collected from the database. Finally, the features set as input are given into the support vector machine classifier. The result of Accuracy was 87.3, Sensitivity was 89.6 and Specificity Index was 83.9 selected as the optimal structure compared to other methods that have been proposed so far [204-224].

Cancer caused by cells goes out of correct pathways. This cell can invade to surrounding healthy cells. There are over 100 different types of cancer and all of them classified by the type of cell that affected. Usually malignancy of gastric cancer starting from layer of the stomach. Gastric cancer has been mentioned as a third cause of death in the world. According to the statistical results, we can see the high frequency of gastric cancer in, Japan, China, Central and South America, Eastern Europe and parts of the middle east. Higher rates usually have been seen group with lower socioeconomic [225-241]. Some signs of this cancer are indigestion or heartburn, vomiting, diarrhea, constipation and having blood in stool. Stomach cancer usually detects in early stage. Each factor that increase the chance of developing cancer is known as a risk factor. Some factors that may increase the risk of stomach cancer are: Age, gender, bacteria, family history, race, diet, previous surgery, smoke and obesity [242-266]. Diagnosis of gastric cancer at first are obtained from laboratory tests and biopsy of stomach with endoscopy. In the next step, cancer may be treated with Surgery, radiation therapy, chemotherapy or immunotherapy [267-284].

Lung cancer is one of the deadliest cancers, such that it causes more deaths compared to breast cancer, colon cancer and prostate cancer and it is mainly because it cannot be diagnosed at early stages due to shortage of symptoms, such that survival rate of patients for 5 years after surgery is only $14 \%$; while diagnosing the disease at early stages increases this probability to $70 \%$. Increasing growth of this disease, difficulty of its diagnosis from images and importance of diagnosis at early stages requires CAD methods with high accuracy. In order to realize this important, a novel algorithm is proposed in this study which selects features online using genetic algorithm and statistical functions. Our purpose is to separate effective features among available features. In order to classify data, a series of data called feature is required for which disease features are used. In many datasets, some features do not affect decisions and they are additional. So selecting an appropriate subset of inputs can be effective in classification accuracy and its speed. For this purpose, genetic algorithm with an objective function based on data sparsity and statistical concepts. The proposed method is implemented and results indicate high accuracy of this algorithm in selecting effective features and increasing accuracy of the classifier compared to basic methods and other studies [285-299].

\subsection{Racial differences in the liability to cancer}

Cancer is a major cause of death with more than 10 million annual patients. It is possible that this number reaches 15 million patients per year by 2020. Though chemotherapy has largely been successful in controlling and treating cancer, live tissue damage, systemic toxicity and side effects in this method are among the issues that cannot be overlooked. In order to reduce the negative effects of anticancer drugs on normal tissues, we need to design Nano-sized carriers that can pass the safety barriers and body tissues and reach their target site. In this work, the size and zeta potential of Nano-carriers PLGA-Cs-Paclitaxel were evaluated. Chitosan connection in physical or conjugated forms may lead to a significant increase of polydispersity. According to the study carried out on the concentration of Chitosan and the type of absorption, it was concluded that nanoparticles size increases with higher concentrations of Chitosan. The zeta potential will increase, provided the conjugation of Chitosan is higher than physical adsorption [300-311].

We present an optimal control strategy for nonlinear systems with application to the drug therapy of cancer. The tumor growth model is represented by a system of equations from population dynamics which is based on the competition between normal cells and tumor cells. There are quite a number of modern optimization algorithms proposed in the last two decades to solve optimization problems. Particle Swarm Optimization (PSO) and differential evolution (DE) are among the well-known modern optimization algorithms. This research presents a comparative study for min-max constrained optimization using PSO and DE. The comparison is performed on eight benchmark functions f1-f8 [312-322]. New findings have been discovered for the PSO algorithm and the comparison results in this report show that DE generally is better than PSO in term of solution accuracy and robustness in almost all the problems. Generally, from the numerical results and graphic illustrations, we can demonstrate that DE is more efficient and robust compare to PSO, although PSO gives good results in some cases.

Elevated expression of EGFR is a frequent genetic abnormality seen in colon cancer. The monoclonal antibody cetuximab binds to EGFR and thus provides an opportunity to create both imaging and therapies that target this receptor. The main goal of this study was to optimize the radioimmunoconjugation of monoclonal anti-EGFR with 177Lu as a potential molecular tracer for colon cancer radio immunotherapy (RIT). Cetuximab was labeled with lutetium-177 using DOTA as chelator. Radiochemical purity and stability in buffer and human blood serum were determined using thin layer chromatography. The integrity of the radiolabeled antibody was checked by SDS-PAGE. Bio distribution study of 177Lu-DOTA-cetuximab was performed in mice at 2, 24, 48 and 72 hours after injection. Immunoreactivity and toxicity of the complex were tested on SW480 colon cancer cell line. Results: The efficiency of antibody labeling was more than $98 \% \pm 1$. The in vitro stability of the labeled product inhuman serum after $96 \mathrm{~h}$ was $83 \pm 2 \%$. There was no fragmentation in the labeled antibody during SDS-PAGE protocol. The highest $\% \mathrm{ID} / \mathrm{g}$ was observed in the blood, liver and lungs. The immunoreactivity of the complex was $91 \pm 1 \%$. At a concentration of $1 \mathrm{nM}$, the complex killed $22 \pm 3 \%$ of SW480 cells. At $16 \mathrm{nM}, 82 \pm 5 \%$ of the cells were killed. Radio conjugate of cetuximab and $177 \mathrm{Lu}$ were successfully produced and characterized as radiopharmaceutical. The results showed that the new complex could be considered for further evaluation in animals and possibly in humans as a new radiopharmaceutical for use in radio immunotherapy against colon cancer [323-343].

Cancer stem cells (CSCs) are rare sub-population of tumor with ability to differentiate and self-renew. Some properties of CSCs such as increased ability to repair damaged DNA/RNA, as well as increased expression of transporters responsible for drug efflux make them main agents for resistance to chemotherapy. In colon cancer, FOLFOX is a common therapy. In this study, we have analyzed the effects of FOLFOX on CSCs population of colon cancer cell line. Results show that in addition to a dose-dependent reduction in cell viability, FOLFOX caused a decrease in SP cells relative to untreated controls [344-372]. 


\section{Over observations of diseased persons}

\subsection{Over cancer invasion of a victim's body}

The electro-oxidative behavior of tamoxifen (Tam) as an anti-cancer drug was investigated in Britton-Robinson (BR) buffer by differential-pulse adsorptive anodic stripping (DPAdAS) technique. The anodic oxidation peak of Tam was attributed to the cyclization reaction to form the corresponding phenanthrene derivative. Oxidative stripping analysis was successfully applied to the determination of Tam in a bulk pharmaceutical formulation. In this work, to find the best conditions for taking a sharp analytical peak concerning the electro-oxidation of Tam, the effects of different parameters such as; deposition potential, deposition time, $\mathrm{pH}$ and the electro cleaning conditions have been studied and optimized. Then the calibration curve was plotted in the range of 1 to $10 \mu \mathrm{M}$ and the limits of detection (LOD) and quantitation (LOQ) were calculated to be 0.621 and $2.07 \mu \mathrm{M}$, respectively. The mean, standard error and relative standard deviation (RSD) for five replicates of $4.0 \mu \mathrm{M}$ were found to be $4.1 \mu \mathrm{M}, 2.65 \%$ and $3.62 \%$, respectively. To estimate the application potential of the proposed method, the extraction of Tam from tablets containing $20 \mathrm{mg}$ Tam were investigated and optimized. Finally, the proposed method was successfully employed for determination of Tam in spiked physiological samples.

In this work, the electro-oxidative behavior of tamoxifen (Tam) as an anti-breast cancer drug was investigated at different electrolytes such as Britton-Robinson (BR) buffer, $\mathrm{H} 2 \mathrm{SO} 4, \mathrm{HNO} 3, \mathrm{CH} 3 \mathrm{COOH}$ and $\mathrm{H} 3 \mathrm{PO} 4$ by differential-pulse adsorptive anodic stripping (DPAdAS) technique. To investigate the mechanism, we performed chronoamperometry, CV at different scan rates and differential pulse anodic voltammetry (DPAV) on tam-covered glassy carbon electrodes (GCEs). The primary experiments demonstrated that the DPAASV presents a sufficient oxidation peak current at approximately $1.03 \mathrm{~V} \mathrm{vs} \mathrm{Ag} / \mathrm{AgCl}$. Therefore, the effects of different parameters such as electrolytes, deposition potential and deposition time have been studied and optimized. The obtained results shown that the $\mathrm{H} 2 \mathrm{SO} 4$ as electrolyte, -1.4 $\mathrm{V}$ and 30s are the optimal values, respectively. Then the calibration curve was plotted in the range of 0.5 to $80 \mu \mathrm{M}$ and the limits of detection (LOD) and quantitation (LOQ) were calculated to be 0.12 and $0.4 \mu \mathrm{M}$, respectively. The mean, standard error and relative standard deviation (RSD) for 4 replicates of $15 \mu \mathrm{M}$ were found to be $15.57 \mu \mathrm{M}, 3 \%$ and $4 \%$, respectively. To estimate the application potential of the proposed method, the extraction of Tam from tablets containing $20 \mathrm{mg}$ Tam were investigated and optimized.

\subsection{Over embryogenesis of cancer}

For the detection of DNA/RNA hybridization, a new electrochemical biosensor was developed on the basis of the interaction of Doxirubicine (DOX) with 22-mer oligonucleotides (from human Colorectal cancer) a simple bio sensing design to yield an ultrasensitive electrochemical biosensor for cancer biomarker detection on Screen Printed Gold Electrodes (SPGE) without use of any modification on electrode surface perhaps direct detection with the help of electroactive label (DOX) and MicroRNA92a (miRNA) as an biomarker selected for being up-regulated in Colorectal cancer. The biosensor was assembled in two stages the immobilization of the probe that was modified on an SPGE and second stage of target hybridization of completely match strand electroactive label DOX has been used after hybridization process which is an intercalator with our miRNA strands as a redox indicator for amplifying the electrochemical signal of miRNA 92a. For conformation electrochemical techniques including Cyclic Voltammetry (CV) and Differential Pulse Voltammetry (DPV). were used and hybridization was observed successfully. The final biosensor provided a sensitive detection of miRNA 92a with good selectivity.

Based on the researches, one of the most common cancer among the men is malignant prostate cancer. Which seen after surgery and gland removing completely the amount of PSA in patient increases again and available drugs which have severe side effects cannot effect on rising the PSA. One parameter that without it cancer cells are not able to reproduce is Glutamine Amino Acid. With studying humanity biochemical pathway and Glutamine Amino Acid reabsorbing pathways by cancer cells we understand that two material Ursolic Acid and Resveratrol could dock with a lots of Allosteric Enzymes inside the reabsorbing pathway Glutamine Amino Acid by cancer cells. That inactive enzymes therefore more than $90 \%$ reabsorbing pathways Glutamine Amino Acid will be closed. Docking these two materials Ursolic Acid and Resveratrol with Allosteric enzymes reabsorbing pathways Glutamine Amino Acid by cancer cells and inactivating enzymes with software Autodock-vina and QSAR has been checked. Also Curcumin could stimulate Apoptosis in prostate cancer cells. Since three above substances (Resveratrol, Curcumin, Ursolic acid) exist in available compounds like skin of red apple, turmeric and black grapes, men above forty years old can reduce risk of prostate cancer by combining a big apple with some turmeric and black grapes (as a potion or juice). So it can protect from prostate cancer. After prostate surgery, PSA may raise again. Consumption of this potion in these cases can replace current medications with several adverse effects. Since we could find Ursolic Acid in red apple skin and Resveratrol in black grape and Curcumin in Turmeric, we could extraction and combine these three material and with determining the amount of doze make a medicine. Then doing the next steps like animal test, toxic test and human test. Base on human gene plan (HGP) and humanity biochemical pathway lack of Allosteric enzymes which by two material Ursolic Acid and Resveratrol will be inactivate and therefore nonproliferation prostate cancer cells.

Chemotherapy resistance of cancers have become a big challenge in modern medicine. Recently, in order to overcome the drug resistance issue, producing novel drug which used with previous ones as multidrug treatment became an alternative. One of the compounds that have drawn much attention in this regard is chromenes. Chromenes have a heterocyclic structure with gamma benzopyrone, and anti-cancer activities. Studies tried to produce new derivative of chromenes which have better effect on cancer therapy. In this investigation we produced four novel derivatives of chromenes and studied the effect of these compounds on the human acute lymphoblastic leukemia cell line ofMOLT4. A series of novel 4-hydroxycoumarinhas been synthesized via multi-step protocol. The structure of the new compound was established using spectroscopic method (H-NMR, C-NMR). MOLT4cells were cultured in RPMI medium with 10\% fetal bovine serum. The cytotoxic effect of different concentrations $(0,50,250,500$ and $1000 \mathrm{nM})$ of novel synthetic compounds were evaluated by the MTT assay and cell counting after different incubation times $(24,48,72 \mathrm{~h})$. These compounds decreased viability of the MOLT4 cells in a timeand dose-dependent manner. Notably, meaningful differences were found between all concentrations and control groups. However, C2 had fewer IC50 in comparison to other ones. Interestingly, this derivative showed significantly cell toxicity at the concentration of NanoMolar, while previously reported ones have cell toxicity at micro-Molar concentrations. Dihydrochromeno (3, 4-b) chromenes have antineoplastic effects on MOLT4 by inducing of apoptosis. Further studies are needed to find exact mechanisms of its effect.

\subsection{Anatomy and physiology of a ripe cancer}

This systematic review and meta-analysis aimed to critically evaluate the relation between Green Tea (GT) consumption and the risk of breast cancer. Electronic databases were systematically searched for English papers. All case-control and cohort studies in addition to 
randomized clinical trials were included if they assessed the chemo preventive effects of green tea on breast cancer. The quality of included studies was assessed. In the meta-analysis, the odds ratio (OR) was calculated based on the results from those who had the highest amount of GT consumed to the data from subjects with the lowest intake. This systematic review comprised 44 studies. OR in case-control studies suggested that women in the group receiving the highest level of GT had 491 reductions in breast cancer risk compared with those who received the lowest level of GT (summary $\mathrm{OR}=18.4, \mathrm{p}=18134$; $951 \mathrm{CI}$ : 1800 to 189.4). OR in cohort studies showed no significant difference between women with the highest consumption of GT and those who received it at the lowest level (OR=1899, P=1894; 951 CI: 18. 4 to 4843). According to the only clinical trial, treatment with GT could not alter the mammographic density compared to placebo. Epidemiological studies have drawn inconsistent conclusions regarding the association between GT intake and breast cancer risk. Nonetheless, it cannot be concluded that GT consumption may decrease the risk of breast cancer. We did not find any statistically significant reduction of breast cancer risk due to GT consumption in case-control nor cohort studies.

Missing value is an important problem in real-world dataset. Recently sets of techniques have uses emerged for the imputation of missing data. Handling this problem, especially in medical data whose controls hard and costly, seems vital. Cancer refers to a disease in which a group of cells shows uncontrolled growth (higher division than natural cells), invasion (entering to adjacent tissues and disintegrating them) and sometimes metastasis. Without filling the missing data, the results of analysis might be doubtful. We tensor methods used to obtain the missing data. In this study, we first get the missing values using the Bayesian Networks and then use the tensor. Finally, the accuracy of disease diagnosis was estimated through support vector machine(SVM) classifier and RMSE measure. The results suggested that the proposed method is superior to other methods in term of value of error, accuracy, sensitivity and specificity.

Occupational cancers account for a major part of cancers. So far, various occupational factors have been recognized as a risk factor involved in the development of different occupational cancers. Prostate cancer is one of the cancers on which various studies have been carried out to examine the role of occupational exposures. The studies have introduced numerous occupational factors and jobs regarding this cancer. The results of studies in this regard have some contradictions. In this short review, occupational risk factors in the development of occupational cancers have been studied. The focus of this study is mainly on the factors, while occupations have not been examined in depth. Lung cancer is one of the most dangerous diseases that cause a large number of deaths. Early detection and analysis can be very helpful for successful treatment. Image segmentation plays a key role in the early detection and diagnosis of lung cancer. K-means algorithm and classic PSO clustering are the most common methods for segmentation that have poor outputs. In this work, we propose a new modified PSO method. The performance of the proposed algorithm is compared to that of $\mathrm{K}$-means and classic PSO clustering. The obtained results show that the new PSO clustering has better results as compared to the other methods. Comparison between the proposed method and classic PSO, in terms of fitness function and convergence of fitness function indicate that the proposed method is more effective in detecting lung cancer.

\subsection{Differences in the locations of cancer sub-units}

The aim of this study was to predict cancer survival according to the role of demographic determinants, psychological factors and tumor grade. In this cross-sectional retrospective study, 350 patients with blood, breast, prostate, lung, stomach and colon cancers (173 patients with cancer survival for more than 2 years and 177 patients with cancer survival for 2 years or less) were selected by convenience sampling method among patients who referred to the American Institute for Cancer Research and Specialized Cancer Treatment Centers in the American Institute for Cancer Research. Data was collected by the Posttraumatic Growth Inventory (PTGI), Inner Strength Questionnaire (ISQ), Bell Object Relations and Reality Testing Inventory (BORRTI), Self-Efficacy Scale for Self-Management (SESSM) and diseasedemographic characteristics questionnaires. Data were analyzed by binary logistic regression analysis using the SPSS 20 software. Age $(\mathrm{P}<0.001)$ and low-grade tumors $(\mathrm{P}<0.01)$ have reverse correlation and the post-traumatic growth has positive significant correlation $(\mathrm{P}<0.01)$ with cancer survival for more than 2 years' survival group. Age $(\mathrm{Exp}=1.10)$, low-grade tumors $(\mathrm{Exp}=4.37)$ and post-traumatic growth $(\mathrm{Exp}=1.06)$ can predict cancer survival for more than 2 years in the cancer patients $(\mathrm{P}<0.01)$. Considering the role of age, tumor grade and post-traumatic growth in the prediction of cancer patients' survival, it can be suggested that preventive programs are important to detect and diagnose cancer and administer tailored interventions in the critical time period.

\section{Conclusion}

Cancer is a major cause of death with more than 10 million annual patients. It is possible that this number reaches 15 million patients per year by 2020. Though chemotherapy has largely been successful in controlling and treating cancer, live tissue damage, systemic toxicity and side effects in this method are among the issues that cannot be overlooked. In order to reduce the negative effects of anticancer drugs on normal tissues, we need to design Nano-sized carriers that can pass the safety barriers and body tissues and reach their target site. In this research, the size and zeta potential of Nano-carriers PLGA-Cs-Paclitaxel were evaluated. Chitosan connection in physical or conjugated forms may lead to a significant increase of polydispersity. According to the study carried out on the concentration of Chitosan and the type of absorption, it was concluded that nanoparticles size increases with higher concentrations of Chitosan. The zeta potential will increase, provided the conjugation of Chitosan is higher than physical adsorption.

\section{References}

[1] A. Heidari, C. Brown, "Study of Composition and Morphology of Cadmium Oxide (CdO) Nanoparticles for Eliminating Cancer Cells", J Nanomed Res., Volume 2, Issue 5, 20 Pages, 2015

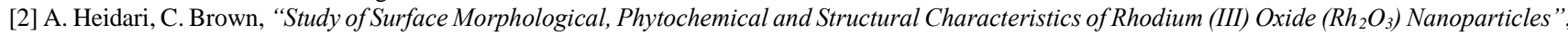
International Journal of Pharmacology, Phytochemistry and Ethnomedicine, Volume 1, Issue 1, Pages 15-19, 2015.

[3] A. Heidari, “An Experimental Biospectroscopic Study on Seminal Plasma in Determination of Semen Quality for Evaluation of Male Infertility", Int J Adv Technol 7: e007, 2016.

[4] A. Heidari, "Extraction and Preconcentration of N-Tolyl-Sulfonyl-Phosphoramid-Saeure-Dichlorid as an Anti-Cancer Drug from Plants: A Pharmacognosy Study", J Pharmacogn Nat Prod 2: e103, 2016.

[5] A. Heidari, "A Thermodynamic Study on Hydration and Dehydration of DNA and RNA-Amphiphile Complexes", J Bioeng Biomed Sci S: 006, 2016.

[6] A. Heidari, "Computational Studies on Molecular Structures and Carbonyl and Ketene Groups' Effects of Singlet and Triplet Energies of Azidoketene $O=C=C H-N N N$ and Isocyanatoketene $O=C=C H-N=C=O$ ", J Appl Computat Math 5: e142, 2016.

[7] A. Heidari, "Study of Irradiations to Enhance the Induces the Dissociation of Hydrogen Bonds between Peptide Chains and Transition from Helix Structure to Random Coil Structure Using ATR-FTIR, Raman and ${ }^{1} H N M R$ Spectroscopies”, J Biomol Res Ther 5: e146, 2016. 
[8] A. Heidari, "Future Prospects of Point Fluorescence Spectroscopy, Fluorescence Imaging and Fluorescence Endoscopy in Photodynamic Therapy (PDT) for Cancer Cells", J Bioanal Biomed 8: e135, 2016.

[9] A. Heidari, "A Bio-Spectroscopic Study of DNA Density and Color Role as Determining Factor for Absorbed Irradiation in Cancer Cells", Adv Cancer Prev 1: e102, 2016.

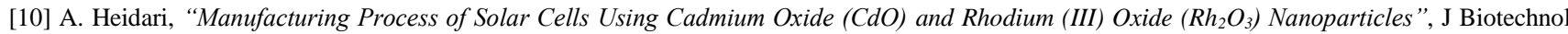
Biomater 6: e125, 2016.

[11] A. Heidari, "A Novel Experimental and Computational Approach to Photobiosimulation of Telomeric DNA/RNA: A Biospectroscopic and Photobiological Study", J Res Development 4: 144, 2016.

[12] A. Heidari, "Biochemical and Pharmacodynamical Study of Microporous Molecularly Imprinted Polymer Selective for Vancomycin, Teicoplanin, Oritavancin, Telavancin and Dalbavancin Binding”, Biochem Physiol 5: e146, 2016.

[13] A. Heidari, "Anti-Cancer Effect of UV Irradiation at Presence of Cadmium Oxide (CdO) Nanoparticles on DNA of Cancer Cells: A Photodynamic Therapy Study”, Arch Cancer Res. 4: 1, 2016.

[14] A. Heidari, "Biospectroscopic Study on Multi-Component Reactions (MCRs) in Two A-Type and B-Type Conformations of Nucleic Acids to Determine Ligand Binding Modes, Binding Constant and Stability of Nucleic Acids in Cadmium Oxide (CdO) Nanoparticles-Nucleic Acids Complexes as Anti-Cancer Drugs", Arch Cancer Res. 4: 2, 2016.

[15] A. Heidari, "Simulation of Temperature Distribution of DNA/RNA of Human Cancer Cells Using Time-Dependent Bio-Heat Equation and Nd: YAG Lasers", Arch Cancer Res. 4: 2, 2016.

[16] A. Heidari, "Quantitative Structure-Activity Relationship (QSAR) Approximation for Cadmium Oxide (CdO) and Rhodium (III) Oxide (Rh, $\mathrm{O}_{3}$ ) Nanoparticles as Anti-Cancer Drugs for the Catalytic Formation of Proviral DNA from Viral RNA Using Multiple Linear and Non-Linear Correlation Approach”, Ann Clin Lab Res. 4: 1, 2016.

[17] A. Heidari, "Biomedical Study of Cancer Cells DNA Therapy Using Laser Irradiations at Presence of Intelligent Nanoparticles”, J Biomedical Sci. 5: 2,2016 .

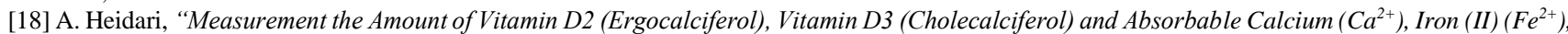
Magnesium $\left(\mathrm{Mg}^{2+}\right)$, Phosphate $\left(\mathrm{PO}^{4-}\right)$ and Zinc $\left(\mathrm{Zn}^{2+}\right)$ in Apricot Using High-Performance Liquid Chromatography (HPLC) and Spectroscopic Techniques", J Biom Biostat 7: 292, 2016.

[19] A. Heidari, "Spectroscopy and Quantum Mechanics of the Helium Dimer $\left(\mathrm{He}^{2+}\right)$, Neon Dimer $\left(\mathrm{Ne}^{2+}\right)$, Argon Dimer $\left(\mathrm{Ar}^{2+}\right), \mathrm{Krypton}_{\mathrm{Dimer}}\left(\mathrm{Kr}^{2+}\right)$, Xenon Dimer $\left(\mathrm{X}^{2+}\right)$, Radon Dimer $\left(\mathrm{Rn}^{2+}\right)$ and Ununoctium Dimer $\left(U u o^{2+}\right)$ Molecular Cations”, Chem Sci J 7: e112, 2016.

[20] A. Heidari, "Human Toxicity Photodynamic Therapy Studies on DNA/RNA Complexes as a Promising New Sensitizer for the Treatment of Malignant Tumors Using Bio-Spectroscopic Techniques”, J Drug Metab Toxicol 7: e129, 2016.

[21] A. Heidari, "Novel and Stable Modifications of Intelligent Cadmium Oxide (CdO) Nanoparticles as Anti-Cancer Drug in Formation of Nucleic Acids Complexes for Human Cancer Cells' Treatment”, Biochem Pharmacol (Los Angel) 5: 207, 2016.

[22] A. Heidari, "A Combined Computational and QM/MM Molecular Dynamics Study on Boron Nitride Nanotubes (BNNTs), Amorphous Boron Nitride Nanotubes (a-BNNTs) and Hexagonal Boron Nitride Nanotubes ( $h-B N N T s)$ as Hydrogen Storage”, Struct Chem Crystallogr Commun 2: 1, 2016.

[23] A. Heidari, "Pharmaceutical and Analytical Chemistry Study of Cadmium Oxide (CdO) Nanoparticles Synthesis Methods and Properties as AntiCancer Drug and its Effect on Human Cancer Cells", Pharm Anal Chem Open Access 2: 113, 2016.

[24] A. Heidari, "A Chemotherapeutic and Biospectroscopic Investigation of the Interaction of Double-Standard DNA/RNA-Binding Molecules with Cadmium Oxide (CdO) and Rhodium (III) Oxide $\left(\mathrm{Rh}_{2} \mathrm{O}_{3}\right)$ Nanoparticles as Anti-Cancer Drugs for Cancer Cells' Treatment”, Chemo Open Access 5: e129, 2016.

[25] A. Heidari, "Pharmacokinetics and Experimental Therapeutic Study of DNA and Other Biomolecules Using Lasers: Advantages and Applications", J Pharmacokinet Exp Ther 1: e005, 2016.

[26] A. Heidari, "Determination of Ratio and Stability Constant of DNA/RNA in Human Cancer Cells and Cadmium Oxide (CdO) Nanoparticles Complexes Using Analytical Electrochemical and Spectroscopic Techniques”, Insights Anal Electrochem 2: 1, 2016.

[27] A. Heidari, "Discriminate between Antibacterial and Non-Antibacterial Drugs Artificial Neutral Networks of a Multilayer Perceptron (MLP) Type Using a Set of Topological Descriptors”, J Heavy Met Toxicity Dis. 1: 2, 2016.

[28] A. Heidari, "Combined Theoretical and Computational Study of the Belousov-Zhabotinsky Chaotic Reaction and Curtius Rearrangement for Synthesis of Mechlorethamine, Cisplatin, Streptozotocin, Cyclophosphamide, Melphalan, Busulphan and BCNU as Anti-Cancer Drugs”, Insights Med Phys. 1: 2, 2016.

[29] A. Heidari, “A Translational Biomedical Approach to Structural Arrangement of Amino Acids' Complexes: A Combined Theoretical and Computational Study”, Transl Biomed. 7: 2, 2016.

[30] A. Heidari, “Ab Initio and Density Functional Theory (DFT) Studies of Dynamic NMR Shielding Tensors and Vibrational Frequencies of DNA/RNA and Cadmium Oxide (CdO) Nanoparticles Complexes in Human Cancer Cells”, J Nanomedine Biotherapeutic Discov 6: e144, 2016.

[31] A. Heidari, "Molecular Dynamics and Monte-Carlo Simulations for Replacement Sugars in Insulin Resistance, Obesity, LDL Cholesterol, Triglycerides, Metabolic Syndrome, Type 2 Diabetes and Cardiovascular Disease: A Glycobiological Study”, J Glycobiol 5: e111, 2016.

[32] A. Heidari, "Synthesis and Study of 5-[(Phenylsulfonyl)Amino]-1,3,4-Thiadiazole-2-Sulfonamide as Potential Anti-Pertussis Drug Using Chromatography and Spectroscopy Techniques”, Transl Med (Sunnyvale) 6: e138, 2016.

[33] A. Heidari, "Nitrogen, Oxygen, Phosphorus and Sulphur Heterocyclic Anti-Cancer Nano Drugs Separation in the Supercritical Fluid of Ozone (O ${ }_{3}$ ) Using Soave-Redlich-Kwong (SRK) and Pang-Robinson (PR) Equations”, Electronic J Biol 12: 4, 2016.

[34] A. Heidari, “An Analytical and Computational Infrared Spectroscopic Review of Vibrational Modes in Nucleic Acids”, Austin J Anal Pharm Chem. 3 (1): 1058, 2016.

[35] A. Heidari, C. Brown, "Phase, Composition and Morphology Study and Analysis of Os-Pd/HfC Nanocomposites”, Nano Res Appl. 2: 1, 2016.

[36] A. Heidari, C. Brown, "Vibrational Spectroscopic Study of Intensities and Shifts of Symmetric Vibration Modes of Ozone Diluted by Cumene”, International Journal of Advanced Chemistry, 4 (1) 5-9, 2016.

[37] A. Heidari, "Study of the Role of Anti-Cancer Molecules with Different Sizes for Decreasing Corresponding Bulk Tumor Multiple Organs or Tissues", Arch Can Res. 4: 2, 2016.

[38] A. Heidari, "Genomics and Proteomics Studies of Zolpidem, Necopidem, Alpidem, Saripidem, Miroprofen, Zolimidine, Olprinone and Abafungin as Anti-Tumor, Peptide Antibiotics, Antiviral and Central Nervous System (CNS) Drugs”, J Data Mining Genomics \& Proteomics 7: e125, 2016.

[39] A. Heidari, "Pharmacogenomics and Pharmacoproteomics Studies of Phosphodiesterase-5 (PDE5) Inhibitors and Paclitaxel Albumin-Stabilized Nanoparticles as Sandwiched Anti-Cancer Nano Drugs between Two DNA/RNA Molecules of Human Cancer Cells”, J Pharmacogenomics Pharmacoproteomics 7: e153, 2016.

[40] A. Heidari, "Biotranslational Medical and Biospectroscopic Studies of Cadmium Oxide (CdO) Nanoparticles-DNA/RNA Straight and Cycle Chain Complexes as Potent Anti-Viral, Anti-Tumor and Anti-Microbial Drugs: A Clinical Approach”, Transl Biomed. 7: $2,2016$.

[41] A. Heidari, “A Comparative Study on Simultaneous Determination and Separation of Adsorbed Cadmium Oxide (CdO) Nanoparticles on DNA/RNA of Human Cancer Cells Using Biospectroscopic Techniques and Dielectrophoresis (DEP) Method”, Arch Can Res. 4: 2, 2016.

[42] A. Heidari, "Cheminformatics and System Chemistry of Cisplatin, Carboplatin, Nedaplatin, Oxaliplatin, Heptaplatin and Lobaplatin as Anti-Cancer Nano Drugs: A Combined Computational and Experimental Study”, J Inform Data Min 1: 3, 2016.

[43] A. Heidari, "Linear and Non-Linear Quantitative Structure-Anti-Cancer-Activity Relationship (QSACAR) Study of Hydrous Ruthenium (IV) Oxide $\left(\mathrm{RuO}_{2}\right)$ Nanoparticles as Non-Nucleoside Reverse Transcriptase Inhibitors (NNRTIs) and Anti-Cancer Nano Drugs", J Integr Oncol 5: e110, 2016.

[44] A. Heidari, "Synthesis, Characterization and Biospectroscopic Studies of Cadmium Oxide (CdO) Nanoparticles-Nucleic Acids Complexes Absence of Soluble Polymer as a Protective Agent Using Nucleic Acids Condensation and Solution Reduction Method”, J Nanosci Curr Res 1: e101, 2016. 
[45] A. Heidari, “Coplanarity and Collinearity of 4'-Dinonyl-2,2'-Bithiazole in One Domain of Bleomycin and Pingyangmycin to be Responsible for Binding of Cadmium Oxide (CdO) Nanoparticles to DNA/RNA Bidentate Ligands as Anti-Tumor Nano Drug”, Int J Drug Dev \& Res 8: 007-008, 2016.

[46] A. Heidari, “A Pharmacovigilance Study on Linear and Non-Linear Quantitative Structure (Chromatographic) Retention Relationships (QSRR) Models for the Prediction of Retention Time of Anti-Cancer Nano Drugs under Synchrotron Radiations”, J Pharmacovigil 4: e161, 2016.

[47] A. Heidari, "Nanotechnology in Preparation of Semipermeable Polymers", J Adv Chem Eng 6: 157, 2016.

[48] A. Heidari, “A Gastrointestinal Study on Linear and Non-Linear Quantitative Structure (Chromatographic) Retention Relationships (QSRR) Models for Analysis 5-Aminosalicylates Nano Particles as Digestive System Nano Drugs under Synchrotron Radiations”, J Gastrointest Dig Syst 6: e119, 2016.

[49] A. Heidari, "DNA/RNA Fragmentation and Cytolysis in Human Cancer Cells Treated with Diphthamide Nano Particles Derivatives", Biomedical Data Mining 5: e102, 2016.

[50] A. Heidari, "A Successful Strategy for the Prediction of Solubility in the Construction of Quantitative Structure-Activity Relationship (QSAR) and Quantitative Structure-Property Relationship (QSPR) under Synchrotron Radiations Using Genetic Function Approximation (GFA) Algorithm”, J Mol Biol Biotechnol 1: 1, 2016.

[51] A. Heidari, "Computational Study on Molecular Structures of $C_{20}, C_{60}, C_{240}, C_{540}, C_{960}, C_{2160}$ and $C_{3840}$ Fullerene Nano Molecules under Synchrotron Radiations Using Fuzzy Logic”, J Material Sci Eng 5: 282, 2016.

[52] A. Heidari, "Graph Theoretical Analysis of Zigzag Polyhexamethylene Biguanide, Polyhexamethylene Adipamide, Polyhexamethylene Biguanide Gauze and Polyhexamethylene Biguanide Hydrochloride (PHMB) Boron Nitride Nanotubes (BNNTs), Amorphous Boron Nitride Nanotubes (aBNNTs) and Hexagonal Boron Nitride Nanotubes ( $h-B N N T s)$ ', J Appl Computat Math 5: e143, 2016.

[53] A. Heidari, “The Impact of High Resolution Imaging on Diagnosis”, Int J Clin Med Imaging 3: 1000e101, 2016.

[54] A. Heidari, "A Comparative Study of Conformational Behavior of Isotretinoin (13-Cis Retinoic Acid) and Tretinoin (All-Trans Retinoic Acid (ATRA)) Nano Particles as Anti-Cancer Nano Drugs under Synchrotron Radiations Using Hartree-Fock (HF) and Density Functional Theory (DFT) Methods", Insights in Biomed 1: 2, 2016.

[55] A. Heidari, “Advances in Logic, Operations and Computational Mathematics”, J Appl Computat Math 5: 5, 2016.

[56] A. Heidari, "Mathematical Equations in Predicting Physical Behavior", J Appl Computat Math 5: 5, 2016.

[57] A. Heidari, "Chemotherapy a Last Resort for Cancer Treatment”, Chemo Open Access 5: 4, 2016.

[58] A. Heidari, "Separation and Pre-Concentration of Metal Cations-DNA/RNA Chelates Using Molecular Beam Mass Spectrometry with Tunable Vacuum Ultraviolet (VUV) Synchrotron Radiation and Various Analytical Methods”, Mass Spectrom Purif Tech 2: e101, 2016.

[59] A. Heidari, "Yoctosecond Quantitative Structure-Activity Relationship (QSAR) and Quantitative Structure-Property Relationship (QSPR) under Synchrotron Radiations Studies for Prediction of Solubility of Anti-Cancer Nano Drugs in Aqueous Solutions Using Genetic Function Approximation (GFA) Algorithm”, Insight Pharm Res. 1: 1, 2016.

[60] A. Heidari, "Cancer Risk Prediction and Assessment in Human Cells under Synchrotron Radiations Using Quantitative Structure Activity Relationship (QSAR) and Quantitative Structure Properties Relationship (QSPR) Studies”, Int J Clin Med Imaging 3: $516,2016$.

[61] A. Heidari, "A Novel Approach to Biology", Electronic J Biol 12: 4, 2016.

[62] A. Heidari, "Innovative Biomedical Equipment's for Diagnosis and Treatment”, J Bioengineer \& Biomedical Sci 6: 2 , 2016.

[63] A. Heidari, "Integrating Precision Cancer Medicine into Healthcare, Medicare Reimbursement Changes and the Practice of Oncology: Trends in Oncology Medicine and Practices", J Oncol Med \& Pract 1: 2, 2016.

[64] A. Heidari, "Promoting Convergence in Biomedical and Biomaterials Sciences and Silk Proteins for Biomedical and Biomaterials Applications: An Introduction to Materials in Medicine and Bioengineering Perspectives", J Bioengineer \& Biomedical Sci 6: 3, 2016.

[65] A. Heidari, "X-Ray Fluorescence and X-Ray Diffraction Analysis on Discrete Element Modeling of Nano Powder Metallurgy Processes in Optimal Container Design”, J Powder Metall Min 6: 1, 2017.

[66] A. Heidari, "Biomolecular Spectroscopy and Dynamics of Nano-Sized Molecules and Clusters as Cross-Linking-Induced Anti-Cancer and ImmuneOncology Nano Drugs Delivery in DNA/RNA of Human Cancer Cells' Membranes under Synchrotron Radiations: A Payload-Based Perspective”, Arch Chem Res. 1: 2, 2017.

[67] A. Heidari, "Deficiencies in Repair of Double-Standard DNA/RNA-Binding Molecules Identified in Many Types of Solid and Liquid Tumors Oncology in Human Body for Advancing Cancer Immunotherapy Using Computer Simulations and Data Analysis: Number of Mutations in a Synchronous Tumor Varies by Age and Type of Synchronous Cancer", J Appl Bioinforma Comput Biol, 6: 1, 2017.

[68] A. Heidari, "Electronic Coupling among the Five Nanomolecules Shuts Down Quantum Tunneling in the Presence and Absence of an Applied Magnetic Field for Indication of the Dimer or other Provide Different Influences on the Magnetic Behavior of Single Molecular Magnets (SMMs) as Qubits for Quantum Computing”, Glob J Res Rev. 4: 2, 2017.

[69] A. Heidari, "Polymorphism in Nano-Sized Graphene Ligand-Induced Transformation of $A u_{38}-x A g_{x} x C u_{x}(S P h-t B u)_{24}$ to $A u_{36}-x A g_{x} / x C u_{x}(S P h-$ $t B u)_{24}(x=1-12)$ Nanomolecules for Synthesis of $A u_{144}-x A g_{x} / x C u_{x}\left[(S R)_{60},\left(S C_{4}\right)_{60},\left(S C_{6}\right)_{60},\left(S C_{12}\right)_{60},(P E T)_{60},(p-M B A)_{60},(F)_{60},(C l)_{60},(B r)_{60},(I)_{60}\right.$, $(\text { At })_{60},(\text { Uus })_{60}$ and $\left.\left(\mathrm{SC}_{6} \mathrm{H}_{13}\right)_{60}\right]$ Nano Clusters as Anti-Cancer Nano Drugs”, J Nanomater Mol Nanotechnol, 6: 3, 2017.

[70] A. Heidari, "Biomedical Resource Oncology and Data Mining to Enable Resource Discovery in Medical, Medicinal, Clinical, Pharmaceutical, Chemical and Translational Research and Their Applications in Cancer Research”, Int J Biomed Data Min 6: e103, 2017.

[71] A. Heidari, "Study of Synthesis, Pharmacokinetics, Pharmacodynamics, Dosing, Stability, Safety and Efficacy of Olympiadane Nanomolecules as Agent for Cancer Enzymotherapy, Immunotherapy, Chemotherapy, Radiotherapy, Hormone Therapy and Targeted Therapy under Synchrotorn Radiation", J Dev Drugs 6: e154, 2017.

[72] A. Heidari, "A Novel Approach to Future Horizon of Top Seven Biomedical Research Topics to Watch in 2017: Alzheimer's, Ebola, Hypersomnia, Human Immunodeficiency Virus (HIV), Tuberculosis (TB), Microbiome/Antibiotic Resistance and Endovascular Stroke”, J Bioengineer \& Biomedical Sci 7: e127, 2017.

[73] A. Heidari, “Opinion on Computational Fluid Dynamics (CFD) Technique”, Fluid Mech Open Acc 4: $157,2017$.

[74] A. Heidari, "Concurrent Diagnosis of Oncology Influence Outcomes in Emergency General Surgery for Colorectal Cancer and Multiple Sclerosis (MS) Treatment Using Magnetic Resonance Imaging (MRI) and $A u_{329}(S R)_{84}, A u_{329-x} A g_{x}(S R)_{84}, A u_{144}(S R)_{60}, A u_{68}(S R)_{36}, A u_{30}(S R)_{18}, A u_{102}(S P h)_{44}$, $A u_{38}(S P h)_{24}, A u_{38}\left(S_{2} H_{4} P h\right)_{24}, A u_{21} S(S A d m)_{15}, A u_{36}(p M B A)_{24}$ and $A u_{25}(p M B A)_{18}$ Nano Clusters", J Surgery Emerg Med 1: $21,2017$.

[75] A. Heidari, "Developmental Cell Biology in Adult Stem Cells Death and Autophagy to Trigger a Preventive Allergic Reaction to Common Airborne Allergens under Synchrotron Radiation Using Nanotechnology for Therapeutic Goals in Particular Allergy Shots (Immunotherapy)", Cell Biol (Henderson, NV) 6: 1, 2017.

[76] A. Heidari, "Changing Metal Powder Characteristics for Elimination of the Heavy Metals Toxicity and Diseases in Disruption of Extracellular Matrix (ECM) Proteins Adjustment in Cancer Metastases Induced by Osteosarcoma, Chondrosarcoma, Carcinoid, Carcinoma, Ewing's Sarcoma, Fibrosarcoma and Secondary Hematopoietic Solid or Soft Tissue Tumors”, J Powder Metall Min 6: 170, 2017.

[77] A. Heidari, "Nanomedicine-Based Combination Anti-Cancer Therapy between Nucleic Acids and Anti-Cancer Nano Drugs in Covalent Nano Drugs Delivery Systems for Selective Imaging and Treatment of Human Brain Tumors Using Hyaluronic Acid, Alguronic Acid and Sodium Hyaluronate as Anti-Cancer Nano Drugs and Nucleic Acids Delivery under Synchrotron Radiation”, Am J Drug Deliv 5: 2, 2017.

[78] A. Heidari, “Clinical Trials of Dendritic Cell Therapies for Cancer Exposing Vulnerabilities in Human Cancer Cells' Metabolism and Metabolomics: New Discoveries, Unique Features Inform New Therapeutic Opportunities, Biotech's Bumpy Road to the Market and Elucidating the Biochemical Programs that Support Cancer Initiation and Progression”, J Biol Med Science 1: e103, 2017.

[79] A. Heidari, "The Design Graphene-Based Nanosheets as a New Nanomaterial in Anti-Cancer Therapy and Delivery of Chemotherapeutics and Biological Nano Drugs for Liposomal Anti-Cancer Nano Drugs and Gene Delivery”, Br Biomed Bull 5: 305, 2017. 
[80] A. Heidari, “Integrative Approach to Biological Networks for Emerging Roles of Proteomics, Genomics and Transcriptomics in the Discovery and Validation of Human Colorectal Cancer Biomarkers from DNA/RNA Sequencing Data under Synchrotron Radiation”, Transcriptomics 5: e117, 2017.

[81] A. Heidari, "Elimination of the Heavy Metals Toxicity and Diseases in Disruption of Extracellular Matrix (ECM) Proteins and Cell Adhesion Intelligent Nanomolecules Adjustment in Cancer Metastases Using Metalloenzymes and under Synchrotron Radiation”, Lett Health Biol Sci 2 (2): 1-4, 2017.

[82] A. Heidari, “Treatment of Breast Cancer Brain Metastases through a Targeted Nanomolecule Drug Delivery System Based on Dopamine Functionalized Multi-Wall Carbon Nanotubes (MWCNTs) Coated with Nano Graphene Oxide (GO) and Protonated Polyaniline (PANI) in Situ During the Polymerization of Aniline Autogenic Nanoparticles for the Delivery of Anti-Cancer Nano Drugs under Synchrotron Radiation”, Br J Res, 4 (3): 16, 2017.

[83] A. Heidari, "Sedative, Analgesic and Ultrasound-Mediated Gastrointestinal Nano Drugs Delivery for Gastrointestinal Endoscopic Procedure, Nano Drug-Induced Gastrointestinal Disorders and Nano Drug Treatment of Gastric Acidity”, Res Rep Gastroenterol, 1: 1, 2017.

[84] A. Heidari, "Synthesis, Pharmacokinetics, Pharmacodynamics, Dosing, Stability, Safety and Efficacy of Orphan Nano Drugs to Treat High Cholesterol and Related Conditions and to Prevent Cardiovascular Disease under Synchrotron Radiation”, J Pharm Sci Emerg Drugs 5: 1, 2017.

[85] A. Heidari, "Non-Linear Compact Proton Synchrotrons to Improve Human Cancer Cells and Tissues Treatments and Diagnostics through Particle Therapy Accelerators with Monochromatic Microbeams”, J Cell Biol Mol Sci 2 (1): 1-5, 2017.

[86] A. Heidari, "Design of Targeted Metal Chelation Therapeutics Nanocapsules as Colloidal Carriers and Blood-Brain Barrier (BBB) Translocation to Targeted Deliver Anti-Cancer Nano Drugs into the Human Brain to Treat Alzheimer's Disease under Synchrotron Radiation”, J Nanotechnol Material Sci 4 (2): 1-5, 2017.

[87] R. Gobato, A. Heidari, "Calculations Using Quantum Chemistry for Inorganic Molecule Simulation BeLi $i_{2} S e S i ”$, Science Journal of Analytical Chemistry, Vol. 5, No. 6, Pages 76-85, 2017.

[88] A. Heidari, "Different High-Resolution Simulations of Medical, Medicinal, Clinical, Pharmaceutical and Therapeutics Oncology of Human Lung Cancer Translational Anti-Cancer Nano Drugs Delivery Treatment Process under Synchrotron and X-Ray Radiations”, J Med Oncol. Vol. 1 No. 1: $1,2017$.

[89] A. Heidari, “A Modern Ethnomedicinal Technique for Transformation, Prevention and Treatment of Human Malignant Gliomas Tumors into Human Benign Gliomas Tumors under Synchrotron Radiation”, Am J Ethnomed, Vol. 4 No. 1: 10, 2017.

[90] A. Heidari, “Active Targeted Nanoparticles for Anti-Cancer Nano Drugs Delivery across the Blood-Brain Barrier for Human Brain Cancer Treatment, Multiple Sclerosis (MS) and Alzheimer's Diseases Using Chemical Modifications of Anti-Cancer Nano Drugs or Drug-Nanoparticles through Zika Virus (ZIKV) Nanocarriers under Synchrotron Radiation”, J Med Chem Toxicol, 2 (3): 1-5, 2017.

[91] A. Heidari, "Investigation of Medical, Medicinal, Clinical and Pharmaceutical Applications of Estradiol, Mestranol (Norlutin), Norethindrone (NET), Norethisterone Acetate (NETA), Norethisterone Enanthate (NETE) and Testosterone Nanoparticles as Biological Imaging, Cell Labeling, AntiMicrobial Agents and Anti-Cancer Nano Drugs in Nanomedicines Based Drug Delivery Systems for Anti-Cancer Targeting and Treatment”, Parana Journal of Science and Education (PJSE)-v.3, n.4, (10-19) October 12, 2017.

[92] A. Heidari, “A Comparative Computational and Experimental Study on Different Vibrational Biospectroscopy Methods, Techniques and Applications for Human Cancer Cells in Tumor Tissues Simulation, Modeling, Research, Diagnosis and Treatment”, Open J Anal Bioanal Chem 1 (1): 014-020, 2017.

[93] A. Heidari, “Combination of DNA/RNA Ligands and Linear/Non-Linear Visible-Synchrotron Radiation-Driven N-Doped Ordered Mesoporous Cadmium Oxide (CdO) Nanoparticles Photocatalysts Channels Resulted in an Interesting Synergistic Effect Enhancing Catalytic Anti-Cancer Activity”, Enz Eng 6: 1, 2017.

[94] A. Heidari, "Modern Approaches in Designing Ferritin, Ferritin Light Chain, Transferrin, Beta-2 Transferrin and Bacterioferritin-Based AntiCancer Nano Drugs Encapsulating Nanosphere as DNA-Binding Proteins from Starved Cells (DPS)”, Mod Appro Drug Des. 1 (1). MADD.000504. 2017.

[95] A. Heidari, "Potency of Human Interferon $\beta-1 a$ and Human Interferon $\beta-1 b$ in Enzymotherapy, Immunotherapy, Chemotherapy, Radiotherapy, Hormone Therapy and Targeted Therapy of Encephalomyelitis Disseminate/Multiple Sclerosis (MS) and Hepatitis A, B, C, D, E, F and G Virus Enter and Targets Liver Cells", J Proteomics Enzymol 6: 1, 2017.

[96] A. Heidari, "Transport Therapeutic Active Targeting of Human Brain Tumors Enable Anti-Cancer Nanodrugs Delivery across the Blood-Brain Barrier (BBB) to Treat Brain Diseases Using Nanoparticles and Nanocarriers under Synchrotron Radiation", J Pharm Pharmaceutics 4 (2): 1-5, 2017.

[97] A. Heidari, C. Brown, "Combinatorial Therapeutic Approaches to DNA/RNA and Benzylpenicillin (Penicillin G), Fluoxetine Hydrochloride (Prozac and Sarafem), Propofol (Diprivan), Acetylsalicylic Acid (ASA) (Aspirin), Naproxen Sodium (Aleve and Naprosyn) and Dextromethamphetamine Nanocapsules with Surface Conjugated DNA/RNA to Targeted Nano Drugs for Enhanced Anti-Cancer Efficacy and Targeted Cancer Therapy Using Nano Drugs Delivery Systems", Ann Adv Chem. 1 (2): 061-069, 2017.

[98] A. Heidari, "High-Resolution Simulations of Human Brain Cancer Translational Nano Drugs Delivery Treatment Process under Synchrotron Radiation", J Transl Res. 1 (1): 1-3, 2017.

[99] A. Heidari, "Investigation of Anti-Cancer Nano Drugs' Effects' Trend on Human Pancreas Cancer Cells and Tissues Prevention, Diagnosis and Treatment Process under Synchrotron and X-Ray Radiations with the Passage of Time Using Mathematica”, Current Trends Anal Bioanal Chem, 1 (1): $36-41,2017$.

[100] A. Heidari, "Pros and Cons Controversy on Molecular Imaging and Dynamics of Double-Standard DNA/RNA of Human Preserving Stem CellsBinding Nano Molecules with Androgens/Anabolic Steroids (AAS) or Testosterone Derivatives through Tracking of Helium-4 Nucleus (Alpha Particle) Using Synchrotron Radiation”, Arch Biotechnol Biomed. 1 (1): 067-0100, 2017.

[101] A. Heidari, "Visualizing Metabolic Changes in Probing Human Cancer Cells and Tissues Metabolism Using Vivo ${ }^{1} H$ or Proton NMR, ${ }^{13}$ C NMR, ${ }^{15}$ N NMR and ${ }^{31}$ P NMR Spectroscopy and Self-Organizing Maps under Synchrotron Radiation”, SOJ Mater Sci Eng 5 (2): 1-6, 2017.

[102] A. Heidari, "Cavity Ring-Down Spectroscopy (CRDS), Circular Dichroism Spectroscopy, Cold Vapour Atomic Fluorescence Spectroscopy and Correlation Spectroscopy Comparative Study on Malignant and Benign Human Cancer Cells and Tissues with the Passage of Time under Synchrotron Radiation", Enliven: Challenges Cancer Detect Ther 4 (2): e001, 2017.

[103] A. Heidari, "Laser Spectroscopy, Laser-Induced Breakdown Spectroscopy and Laser-Induced Plasma Spectroscopy Comparative Study on Malignant and Benign Human Cancer Cells and Tissues with the Passage of Time under Synchrotron Radiation”, Int J Hepatol Gastroenterol, 3 (4): 079$084,2017$.

[104] A. Heidari, “Time-Resolved Spectroscopy and Time-Stretch Spectroscopy Comparative Study on Malignant and Benign Human Cancer Cells and Tissues with the Passage of Time under Synchrotron Radiation”, Enliven: Pharmacovigilance and Drug Safety 4 (2): e001, 2017.

[105] A. Heidari, "Overview of the Role of Vitamins in Reducing Negative Effect of Decapeptyl (Triptorelin Acetate or Pamoate Salts) on Prostate Cancer Cells and Tissues in Prostate Cancer Treatment Process through Transformation of Malignant Prostate Tumors into Benign Prostate Tumors under Synchrotron Radiation”, Open J Anal Bioanal Chem 1 (1): 021-026, 2017.

[106] A. Heidari, "Electron Phenomenological Spectroscopy, Electron Paramagnetic Resonance (EPR) Spectroscopy and Electron Spin Resonance (ESR) Spectroscopy Comparative Study on Malignant and Benign Human Cancer Cells and Tissues with the Passage of Time under Synchrotron Radiation", Austin J Anal Pharm Chem. 4 (3): 1091, 2017.

[107] A. Heidari, “Therapeutic Nanomedicine Different High-Resolution Experimental Images and Computational Simulations for Human Brain Cancer Cells and Tissues Using Nanocarriers Deliver DNA/RNA to Brain Tumors under Synchrotron Radiation with the Passage of Time Using Mathematica and MATLAB”, Madridge J Nano Tech. Sci. 2 (2): 77-83, 2017. 
[108] A. Heidari, “A Consensus and Prospective Study on Restoring Cadmium Oxide (CdO) Nanoparticles Sensitivity in Recurrent Ovarian Cancer by Extending the Cadmium Oxide (CdO) Nanoparticles-Free Interval Using Synchrotron Radiation Therapy as Antibody-Drug Conjugate for the Treatment of Limited-Stage Small Cell Diverse Epithelial Cancers”, Cancer Clin Res Rep, 1: 2, e001, 2017.

[109] A. Heidari, "A Novel and Modern Experimental Imaging and Spectroscopy Comparative Study on Malignant and Benign Human Cancer Cells and Tissues with the Passage of Time under White Synchrotron Radiation”, Cancer Sci Res Open Access 4 (2): 1-8, 2017.

[110] A. Heidari, "Different High-Resolution Simulations of Medical, Medicinal, Clinical, Pharmaceutical and Therapeutics Oncology of Human Breast Cancer Translational Nano Drugs Delivery Treatment Process under Synchrotron and X-Ray Radiations”, J Oral Cancer Res 1 (1): $12-17,2017$.

[111] A. Heidari, "Vibrational Decihertz (dHz), Centihertz (cHz), Millihertz ( $\mathrm{mHz}$ ), Microhertz ( $\mu \mathrm{Hz}), \mathrm{Nanohertz} \mathrm{(nHz),} \mathrm{Picohertz} \mathrm{(pHz),} \mathrm{Femtohertz}$ (fHz), Attohertz (aHz), Zeptohertz $(z \mathrm{~Hz})$ and Yoctohertz $(y \mathrm{~Hz})$ Imaging and Spectroscopy Comparative Study on Malignant and Benign Human Cancer Cells and Tissues under Synchrotron Radiation”, International Journal of Biomedicine, 7 (4), 335-340, 2017.

[112] A. Heidari, "Force Spectroscopy and Fluorescence Spectroscopy Comparative Study on Malignant and Benign Human Cancer Cells and Tissues with the Passage of Time under Synchrotron Radiation”, EC Cancer, 2 (5), 239-246, 2017.

[113] A. Heidari, "Photoacoustic Spectroscopy, Photoemission Spectroscopy and Photothermal Spectroscopy Comparative Study on Malignant and Benign Human Cancer Cells and Tissues with the Passage of Time under Synchrotron Radiation”, BAOJ Cancer Res Ther, 3: 3, 045-052, 2017.

[114] A. Heidari, "J-Spectroscopy, Exchange Spectroscopy (EXSY), Nuclear Overhauser Effect Spectroscopy (NOESY) and Total Correlation Spectroscopy (TOCSY) Comparative Study on Malignant and Benign Human Cancer Cells and Tissues under Synchrotron Radiation”, EMS Eng Sci J, 1 (2): 006-013, 2017.

[115] A. Heidari, "Neutron Spin Echo Spectroscopy and Spin Noise Spectroscopy Comparative Study on Malignant and Benign Human Cancer Cells and Tissues with the Passage of Time under Synchrotron Radiation”, Int J Biopharm Sci, 1: 103-107, 2017.

[116] A. Heidari, "Vibrational Decahertz (daHz), Hectohertz (hHz), Kilohertz (kHz), Megahertz (MHz), Gigahertz (GHz), Terahertz (THz), Petahertz $(\mathrm{PHz})$, Exahertz (EHz), Zettahertz $(\mathrm{ZHz})$ and Yottahertz (YHz) Imaging and Spectroscopy Comparative Study on Malignant and Benign Human Cancer Cells and Tissues under Synchrotron Radiation”, Madridge J Anal Sci Instrum, 2 (1): 41-46, 2017.

[117] A. Heidari, "Two-Dimensional Infrared Correlation Spectroscopy, Linear Two-Dimensional Infrared Spectroscopy and Non-Linear Two-Dimensional Infrared Spectroscopy Comparative Study on Malignant and Benign Human Cancer Cells and Tissues under Synchrotron Radiation with the Passage of Time”, J Mater Sci Nanotechnol 6 (1): 101, 2018.

[118] A. Heidari, "Fourier Transform Infrared (FTIR) Spectroscopy, Near-Infrared Spectroscopy (NIRS) and Mid-Infrared Spectroscopy (MIRS) Comparative Study on Malignant and Benign Human Cancer Cells and Tissues under Synchrotron Radiation with the Passage of Time”, Int J Nanotechnol Nanomed, Volume 3, Issue 1, Pages 1-6, 2018.

[119] A. Heidari, "Infrared Photo Dissociation Spectroscopy and Infrared Correlation Table Spectroscopy Comparative Study on Malignant and Benign Human Cancer Cells and Tissues under Synchrotron Radiation with the Passage of Time”, Austin Pharmacol Pharm, 3 (1): 1011, 2018.

[120] A. Heidari, "Novel and Transcendental Prevention, Diagnosis and Treatment Strategies for Investigation of Interaction among Human Blood Cancer Cells, Tissues, Tumors and Metastases with Synchrotron Radiation under Anti-Cancer Nano Drugs Delivery Efficacy Using MATLAB Modeling and Simulation”, Madridge J Nov Drug Res, 1 (1): 18-24, 2017.

[121] A. Heidari, "Comparative Study on Malignant and Benign Human Cancer Cells and Tissues with the Passage of Time under Synchrotron Radiation", Open Access J Trans Med Res, 2 (1): 00026-00032, 2018.

[122] M. R. R. Gobato, R. Gobato, A. Heidari, "Planting of Jaboticaba Trees for Landscape Repair of Degraded Area", Landscape Architecture and Regional Planning, Vol. 3, No. 1, 2018, Pages 1-9, 2018.

[123] A. Heidari, "Fluorescence Spectroscopy, Phosphorescence Spectroscopy and Luminescence Spectroscopy Comparative Study on Malignant and Benign Human Cancer Cells and Tissues under Synchrotron Radiation with the Passage of Time”, SM J Clin. Med. Imaging, 4 (1): $1018,2018$.

[124] A. Heidari, "Nuclear Inelastic Scattering Spectroscopy (NISS) and Nuclear Inelastic Absorption Spectroscopy (NIAS) Comparative Study on Malignant and Benign Human Cancer Cells and Tissues under Synchrotron Radiation”, Int J Pharm Sci, 2 (1): 1-14, 2018.

[125] A. Heidari, "X-Ray Diffraction (XRD), Powder X-Ray Diffraction (PXRD) and Energy-Dispersive X-Ray Diffraction (EDXRD) Comparative Study on Malignant and Benign Human Cancer Cells and Tissues under Synchrotron Radiation”, J Oncol Res; 2 (1): 1-14, 2018.

[126] A. Heidari, "Correlation Two-Dimensional Nuclear Magnetic Resonance (NMR) (2D-NMR) (COSY) Imaging and Spectroscopy Comparative Study on Malignant and Benign Human Cancer Cells and Tissues under Synchrotron Radiation”, EMS Can Sci, 1-1-001, 2018.

[127] A. Heidari, "Thermal Spectroscopy, Photothermal Spectroscopy, Thermal Microspectroscopy, Photothermal Microspectroscopy, Thermal Macrospectroscopy and Photothermal Macrospectroscopy Comparative Study on Malignant and Benign Human Cancer Cells and Tissues with the Passage of Time under Synchrotron Radiation”, SM J Biometrics Biostat, 3 (1): 1024, 2018.

[128] A. Heidari, “A Modern and Comprehensive Experimental Biospectroscopic Comparative Study on Human Common Cancers' Cells, Tissues and Tumors before and after Synchrotron Radiation Therapy”, Open Acc J Oncol Med. 1 (1), 2018.

[129] A. Heidari, "Heteronuclear Correlation Experiments such as Heteronuclear Single-Quantum Correlation Spectroscopy (HSQC), Heteronuclear Multiple-Quantum Correlation Spectroscopy (HMQC) and Heteronuclear Multiple-Bond Correlation Spectroscopy (HMBC) Comparative Study on Malignant and Benign Human Endocrinology and Thyroid Cancer Cells and Tissues under Synchrotron Radiation”, J Endocrinol Thyroid Res, 3 (1): 555603, 2018.

[130] A. Heidari, "Nuclear Resonance Vibrational Spectroscopy (NRVS), Nuclear Inelastic Scattering Spectroscopy (NISS), Nuclear Inelastic Absorption Spectroscopy (NIAS) and Nuclear Resonant Inelastic X-Ray Scattering Spectroscopy (NRIXSS) Comparative Study on Malignant and Benign Human Cancer Cells and Tissues under Synchrotron Radiation”, Int J Bioorg Chem Mol Biol. 6 (1e): 1-5, 2018.

[131] A. Heidari, "A Novel and Modern Experimental Approach to Vibrational Circular Dichroism Spectroscopy and Video Spectroscopy Comparative Study on Malignant and Benign Human Cancer Cells and Tissues with the Passage of Time under White and Monochromatic Synchrotron Radiation”, Glob J Endocrinol Metab. 1 (3). GJEM. 000514-000519, 2018.

[132] A. Heidari, "Pros and Cons Controversy on Heteronuclear Correlation Experiments such as Heteronuclear Single-Quantum Correlation Spectroscopy (HSQC), Heteronuclear Multiple-Quantum Correlation Spectroscopy (HMQC) and Heteronuclear Multiple-Bond Correlation Spectroscopy $(H M B C)$ Comparative Study on Malignant and Benign Human Cancer Cells and Tissues under Synchrotron Radiation”, EMS Pharma J. 1 (1): 002008,2018

[133] A. Heidari, “A Modern Comparative and Comprehensive Experimental Biospectroscopic Study on Different Types of Infrared Spectroscopy of Malignant and Benign Human Cancer Cells and Tissues with the Passage of Time under Synchrotron Radiation”, J Analyt Molecul Tech. 3 (1): 8 , 2018.

[134] A. Heidari, "Investigation of Cancer Types Using Synchrotron Technology for Proton Beam Therapy: An Experimental Biospectroscopic Comparative Study”, European Modern Studies Journal, Vol. 2, No. 1, 13-29, 2018.

[135] A. Heidari, "Saturated Spectroscopy and Unsaturated Spectroscopy Comparative Study on Malignant and Benign Human Cancer Cells and Tissues with the Passage of Time under Synchrotron Radiation”, Imaging J Clin Medical Sci. 5 (1): 001-007, 2018.

[136] A. Heidari, "Small-Angle Neutron Scattering (SANS) and Wide-Angle X-Ray Diffraction (WAXD) Comparative Study on Malignant and Benign Human Cancer Cells and Tissues under Synchrotron Radiation”, Int J Bioorg Chem Mol Biol. 6 (2e): 1-6, 2018.

[137] A. Heidari, "Investigation of Bladder Cancer, Breast Cancer, Colorectal Cancer, Endometrial Cancer, Kidney Cancer, Leukemia, Liver, Lung Cancer, Melanoma, Non-Hodgkin Lymphoma, Pancreatic Cancer, Prostate Cancer, Thyroid Cancer and Non-Melanoma Skin Cancer Using Synchrotron Technology for Proton Beam Therapy: An Experimental Biospectroscopic Comparative Study”, Ther Res Skin Dis 1 (1), 2018.

[138] A. Heidari, "Attenuated Total Reflectance Fourier Transform Infrared (ATR-FTIR) Spectroscopy, Micro-Attenuated Total Reflectance Fourier Transform Infrared (Micro-ATR-FTIR) Spectroscopy and Macro-Attenuated Total Reflectance Fourier Transform Infrared (Macro-ATR-FTIR) Spectroscopy Comparative Study on Malignant and Benign Human Cancer Cells and Tissues under Synchrotron Radiation with the Passage of Time”, International Journal of Chemistry Papers, 2 (1): 1-12, 2018. 
[139] A. Heidari, "Mössbauer Spectroscopy, Mössbauer Emission Spectroscopy and ${ }^{57}$ Fe Mössbauer Spectroscopy Comparative Study on Malignant and Benign Human Cancer Cells and Tissues under Synchrotron Radiation”, Acta Scientific Cancer Biology 2.3: 17-20, 2018.

[140] A. Heidari, "Comparative Study on Malignant and Benign Human Cancer Cells and Tissues under Synchrotron Radiation with the Passage of Time”, Organic \& Medicinal Chem IJ. 6 (1): 555676, 2018.

[141] A. Heidari, "Correlation Spectroscopy, Exclusive Correlation Spectroscopy and Total Correlation Spectroscopy Comparative Study on Malignant and Benign Human AIDS-Related Cancers Cells and Tissues with the Passage of Time under Synchrotron Radiation”, Int J Bioanal Biomed. 2 (1): 001-007, 2018.

[142] A. Heidari, "Biomedical Instrumentation and Applications of Biospectroscopic Methods and Techniques in Malignant and Benign Human Cancer Cells and Tissues Studies under Synchrotron Radiation and Anti-Cancer Nano Drugs Delivery”, Am J Nanotechnol Nanomed. 1 (1): 001-009, 2018.

[143] A. Heidari, "Vivo ${ }^{1}$ H or Proton NMR, ${ }^{13}$ C NMR, ${ }^{15} N$ NMR and ${ }^{31} P$ NMR Spectroscopy Comparative Study on Malignant and Benign Human Cancer Cells and Tissues under Synchrotron Radiation”, Ann Biomet Biostat. 1 (1): 1001, 2018.

[144] A. Heidari, "Grazing-Incidence Small-Angle Neutron Scattering (GISANS) and Grazing-Incidence X-Ray Diffraction (GIXD) Comparative Study on Malignant and Benign Human Cancer Cells, Tissues and Tumors under Synchrotron Radiation”, Ann Cardiovasc Surg. 1 (2): $1006,2018$.

[145] A. Heidari, "Adsorption Isotherms and Kinetics of Multi-Walled Carbon Nanotubes (MWCNTs), Boron Nitride Nanotubes (BNNTs), Amorphous Boron Nitride Nanotubes (a-BNNTs) and Hexagonal Boron Nitride Nanotubes ( $h-B N N T s)$ for Eliminating Carcinoma, Sarcoma, Lymphoma, Leukemia, Germ Cell Tumor and Blastoma Cancer Cells and Tissues”, Clin Med Rev Case Rep 5: 201, 2018.

[146] A. Heidari, “Correlation Spectroscopy (COSY), Exclusive Correlation Spectroscopy (ECOSY), Total Correlation Spectroscopy (TOCSY), Incredible Natural-Abundance Double-Quantum Transfer Experiment (INADEQUATE), Heteronuclear Single-Quantum Correlation Spectroscopy (HSQC), Heteronuclear Multiple-Bond Correlation Spectroscopy (HMBC), Nuclear Overhauser Effect Spectroscopy (NOESY) and Rotating Frame Nuclear Overhauser Effect Spectroscopy (ROESY) Comparative Study on Malignant and Benign Human Cancer Cells and Tissues under Synchrotron Radiation", Acta Scientific Pharmaceutical Sciences 2.5: 30-35, 2018.

[147] A. Heidari, "Small-Angle X-Ray Scattering (SAXS), Ultra-Small Angle X-Ray Scattering (USAXS), Fluctuation X-Ray Scattering (FXS), WideAngle X-Ray Scattering (WAXS), Grazing-Incidence Small-Angle X-Ray Scattering (GISAXS), Grazing-Incidence Wide-Angle X-Ray Scattering (GIWAXS), Small-Angle Neutron Scattering (SANS), Grazing-Incidence Small-Angle Neutron Scattering (GISANS), X-Ray Diffraction (XRD), Powder X-Ray Diffraction (PXRD), Wide-Angle X-Ray Diffraction (WAXD), Grazing-Incidence X-Ray Diffraction (GIXD) and Energy-Dispersive $X$-Ray Diffraction (EDXRD) Comparative Study on Malignant and Benign Human Cancer Cells and Tissues under Synchrotron Radiation", Oncol Res Rev, Volume 1 (1): 1-10, 2018.

[148] A. Heidari, "Pump-Probe Spectroscopy and Transient Grating Spectroscopy Comparative Study on Malignant and Benign Human Cancer Cells and Tissues with the Passage of Time under Synchrotron Radiation”, Adv Material Sci Engg, Volume 2, Issue 1, Pages 1-7, 2018.

[149] A. Heidari, "Grazing-Incidence Small-Angle X-Ray Scattering (GISAXS) and Grazing-Incidence Wide-Angle X-Ray Scattering (GIWAXS) Comparative Study on Malignant and Benign Human Cancer Cells and Tissues under Synchrotron Radiation”, Insights Pharmacol Pharm Sci 1 (1): 1$8,2018$.

[150] A. Heidari, “Acoustic Spectroscopy, Acoustic Resonance Spectroscopy and Auger Spectroscopy Comparative Study on Anti-Cancer Nano Drugs Delivery in Malignant and Benign Human Cancer Cells and Tissues with the Passage of Time under Synchrotron Radiation”, Nanosci Technol 5 (1): $1-9,2018$.

[151] A. Heidari, "Niobium, Technetium, Ruthenium, Rhodium, Hafnium, Rhenium, Osmium and Iridium Ions Incorporation into the Nano Polymeric Matrix (NPM) by Immersion of the Nano Polymeric Modified Electrode (NPME) as Molecular Enzymes and Drug Targets for Human Cancer Cells, Tissues and Tumors Treatment under Synchrotron and Synchrocyclotron Radiations", Nanomed Nanotechnol, 3 (2): 000138, 2018.

[152] A. Heidari, "Homonuclear Correlation Experiments such as Homonuclear Single-Quantum Correlation Spectroscopy (HSQC), Homonuclear Multiple-Quantum Correlation Spectroscopy (HMQC) and Homonuclear Multiple-Bond Correlation Spectroscopy (HMBC) Comparative Study on Malignant and Benign Human Cancer Cells and Tissues under Synchrotron Radiation”, Austin J Proteomics Bioinform \& Genomics. 5 (1): $1024,2018$.

[153] A. Heidari, "Atomic Force Microscopy Based Infrared (AFM-IR) Spectroscopy and Nuclear Resonance Vibrational Spectroscopy Comparative Study on Malignant and Benign Human Cancer Cells and Tissues under Synchrotron Radiation with the Passage of Time”, J Appl Biotechnol Bioeng. 5 (3): 142-148, 2018.

[154] A. Heidari, “Time-Dependent Vibrational Spectral Analysis of Malignant and Benign Human Cancer Cells and Tissues under Synchrotron Radiation”, J Cancer Oncol, 2 (2): 000124, 2018.

[155] A. Heidari, "Palauamine and Olympiadane Nano Molecules Incorporation into the Nano Polymeric Matrix (NPM) by Immersion of the Nano Polymeric Modified Electrode (NPME) as Molecular Enzymes and Drug Targets for Human Cancer Cells, Tissues and Tumors Treatment under Synchrotron and Synchrocyclotron Radiations", Arc Org Inorg Chem Sci 3 (1), 2018.

[156] R. Gobato, A. Heidari, "Infrared Spectrum and Sites of Action of Sanguinarine by Molecular Mechanics and ab initio Methods", International Journal of Atmospheric and Oceanic Sciences. Vol. 2, No. 1, pp. 1-9, 2018.

[157] A. Heidari, "Angelic Acid, Diabolic Acids, Draculin and Miraculin Nano Molecules Incorporation into the Nano Polymeric Matrix (NPM) by Immersion of the Nano Polymeric Modified Electrode (NPME) as Molecular Enzymes and Drug Targets for Human Cancer Cells, Tissues and Tumors Treatment Under Synchrotron and Synchrocyclotron Radiations”, Med \& Analy Chem Int J, 2 (1): $000111,2018$.

[158] A. Heidari, "Gamma Linolenic Methyl Ester, 5-Heptadeca-5,8,11-Trienyl 1,3,4-Oxadiazole-2-Thiol, Sulphoquinovosyl Diacyl Glycerol, Ruscogenin, Nocturnoside B, Protodioscine B, Parquisoside-B, Leiocarposide, Narangenin, 7-Methoxy Hespertin, Lupeol, Rosemariquinone, Rosmanol and Rosemadiol Nano Molecules Incorporation into the Nano Polymeric Matrix (NPM) by Immersion of the Nano Polymeric Modified Electrode (NPME) as Molecular Enzymes and Drug Targets for Human Cancer Cells, Tissues and Tumors Treatment under Synchrotron and Synchrocyclotron Radiations", Int J Pharma Anal Acta, 2 (1): 007-014, 2018.

[159] A. Heidari, "Fourier Transform Infrared (FTIR) Spectroscopy, Attenuated Total Reflectance Fourier Transform Infrared (ATR-FTIR) Spectroscopy, Micro-Attenuated Total Reflectance Fourier Transform Infrared (Micro-ATR-FTIR) Spectroscopy, Macro-Attenuated Total Reflectance Fourier Transform Infrared (Macro-ATR-FTIR) Spectroscopy, Two-Dimensional Infrared Correlation Spectroscopy, Linear Two-Dimensional Infrared Spectroscopy, Non-Linear Two-Dimensional Infrared Spectroscopy, Atomic Force Microscopy Based Infrared (AFM-IR) Spectroscopy, Infrared Photodissociation Spectroscopy, Infrared Correlation Table Spectroscopy, Near-Infrared Spectroscopy (NIRS), Mid-Infrared Spectroscopy (MIRS), Nuclear Resonance Vibrational Spectroscopy, Thermal Infrared Spectroscopy and Photothermal Infrared Spectroscopy Comparative Study on Malignant and Benign Human Cancer Cells and Tissues under Synchrotron Radiation with the Passage of Time”, Glob Imaging Insights, Volume 3 (2): $1-14,2018$.

[160] A. Heidari, "Heteronuclear Single-Quantum Correlation Spectroscopy (HSQC) and Heteronuclear Multiple-Bond Correlation Spectroscopy $(H M B C)$ Comparative Study on Malignant and Benign Human Cancer Cells, Tissues and Tumors under Synchrotron and Synchrocyclotron Radiations", Chronicle of Medicine and Surgery 2.3: 144-156, 2018.

[161] A. Heidari, "Tetrakis [3, 5-bis (Trifluoromethyl) Phenyl] Borate (BARF)-Enhanced Precatalyst Preparation Stabilization and Initiation (EPPSI) Nano Molecules", Medical Research and Clinical Case Reports 2.1: 113-126, 2018.

[162] A. Heidari, "Sydnone, Münchnone, Montréalone, Mogone, Montelukast, Quebecol and Palau'amine-Enhanced Precatalyst Preparation Stabilization and Initiation (EPPSI) Nano Molecules”, Sur Cas Stud Op Acc J. 1 (3), 2018.

[163] A. Heidari, "Fornacite, Orotic Acid, Rhamnetin, Sodium Ethyl Xanthate (SEX) and Spermine (Spermidine or Polyamine) Nanomolecules Incorporation into the Nanopolymeric Matrix (NPM)", International Journal of Biochemistry and Biomolecules, Vol. 4: Issue 1, Pages 1-19, 2018.

[164] A. Heidari, R. Gobato, "Putrescine, Cadaverine, Spermine and Spermidine-Enhanced Precatalyst Preparation Stabilization and Initiation (EPPSI) Nano Molecules”, Parana Journal of Science and Education (PJSE)-v.4, n.5, (1-14) July 1, 2018.

[165] A. Heidari, "Cadaverine (1,5-Pentanediamine or Pentamethylenediamine), Diethyl Azodicarboxylate (DEAD or DEADCAT) and Putrescine (Tetramethylenediamine) Nano Molecules Incorporation into the Nano Polymeric Matrix (NPM) by Immersion of the Nano Polymeric Modified Electrode 
(NPME) as Molecular Enzymes and Drug Targets for Human Cancer Cells, Tissues and Tumors Treatment under Synchrotron and Synchrocyclotron Radiations", Hiv and Sexual Health Open Access Open Journal. 1 (1): 4-11, 2018.

[166] A. Heidari, "Improving the Performance of Nano-Endofullerenes in Polyaniline Nanostructure-Based Biosensors by Covering Californium Colloidal Nanoparticles with Multi-Walled Carbon Nanotubes”, Journal of Advances in Nanomaterials, Vol. 3, No. 1, Pages 1-28, 2018.

[167] R. Gobato, A. Heidari, "Molecular Mechanics and Quantum Chemical Study on Sites of Action of Sanguinarine Using Vibrational Spectroscopy Based on Molecular Mechanics and Quantum Chemical Calculations”, Malaysian Journal of Chemistry, Vol. 20 (1), 1-23, 2018.

[168] A. Heidari, “Vibrational Biospectroscopic Studies on Anti-cancer Nanopharmaceuticals (Part I)”, Malaysian Journal of Chemistry, Vol. 20 (1), $33-73,2018$

[169] A. Heidari, “Vibrational Biospectroscopic Studies on Anti-cancer Nanopharmaceuticals (Part II)”, Malaysian Journal of Chemistry, Vol. 20 (1), $74-117,2018$

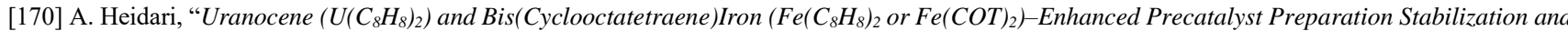
Initiation (EPPSI) Nano Molecules”, Chemistry Reports, Vol. 1, Iss. 2, Pages 1-16, 2018.

[171] A. Heidari, "Biomedical Systematic and Emerging Technological Study on Human Malignant and Benign Cancer Cells and Tissues Biospectroscopic Analysis under Synchrotron Radiation”, Glob Imaging Insights, Volume 3 (3): 1-7, 2018.

[172] A. Heidari, "Deep-Level Transient Spectroscopy and X-Ray Photoelectron Spectroscopy (XPS) Comparative Study on Malignant and Benign Human Cancer Cells and Tissues with the Passage of Time under Synchrotron Radiation”, Res Dev Material Sci. 7(2). RDMS.000659, 2018.

[173] A. Heidari, "C70-Carboxyfullerenes Nano Molecules Incorporation into the Nano Polymeric Matrix (NPM) by Immersion of the Nano Polymeric Modified Electrode (NPME) as Molecular Enzymes and Drug Targets for Human Cancer Cells, Tissues and Tumors Treatment under Synchrotron and Synchrocyclotron Radiations", Glob Imaging Insights, Volume 3 (3): 1-7, 2018.

[174] A. Heidari, "The Effect of Temperature on Cadmium Oxide (CdO) Nanoparticles Produced by Synchrotron Radiation in the Human Cancer Cells, Tissues and Tumors", International Journal of Advanced Chemistry, 6 (2) 140-156, 2018

[175] A. Heidari, “A Clinical and Molecular Pathology Investigation of Correlation Spectroscopy (COSY), Exclusive Correlation Spectroscopy (ECOSY), Total Correlation Spectroscopy (TOCSY), Heteronuclear Single-Quantum Correlation Spectroscopy (HSQC) and Heteronuclear Multiple-Bond Correlation Spectroscopy (HMBC) Comparative Study on Malignant and Benign Human Cancer Cells, Tissues and Tumors under Synchrotron and Synchrocyclotron Radiations Using Cyclotron versus Synchrotron, Synchrocyclotron and the Large Hadron Collider (LHC) for Delivery of Proton and Helium Ion (Charged Particle) Beams for Oncology Radiotherapy”, European Journal of Advances in Engineering and Technology, 5 (7): 414 426, 2018

[176] A. Heidari, "Nano Molecules Incorporation into the Nano Polymeric Matrix (NPM) by Immersion of the Nano Polymeric Modified Electrode (NPME) as Molecular Enzymes and Drug Targets for Human Cancer Cells, Tissues and Tumors Treatment under Synchrotron and Synchrocyclotron Radiations", J Oncol Res; 1 (1): 1-20, 2018.

[177] A. Heidari, "Use of Molecular Enzymes in the Treatment of Chronic Disorders", Canc Oncol Open Access J. 1 (1): 12-15, 2018.

[178] A. Heidari, "Vibrational Biospectroscopic Study and Chemical Structure Analysis of Unsaturated Polyamides Nanoparticles as Anti-Cancer Polymeric Nanomedicines Using Synchrotron Radiation”, International Journal of Advanced Chemistry, 6 (2), 167-189, 2018.

[179] A. Heidari, “Adamantane, Irene, Naftazone and Pyridine-Enhanced Precatalyst Preparation Stabilization and Initiation (PEPPSI) Nano Molecules”, Madridge J Nov Drug Res. 2 (1): 61-67, 2018.

[180] A. Heidari, "Heteronuclear Single-Quantum Correlation Spectroscopy (HSQC) and Heteronuclear Multiple-Bond Correlation Spectroscopy (HMBC) Comparative Study on Malignant and Benign Human Cancer Cells and Tissues with the Passage of Time under Synchrotron Radiation”, Madridge J Nov Drug Res, 2 (1): 68-74, 2018.

[181] A. Heidari, R. Gobato, “A Novel Approach to Reduce Toxicities and to Improve Bioavailabilities of DNA/RNA of Human Cancer Cells-Containing Cocaine (Coke), Lysergide (Lysergic Acid Diethyl Amide or LSD), $\Delta^{9}$-Tetrahydrocannabinol (THC) [(-)-trans-49-Tetrahydrocannabinol], Theobromine (Xantheose), Caffeine, Aspartame (APM) (NutraSweet) and Zidovudine (ZDV) [Azidothymidine (AZT)] as Anti-Cancer Nano Drugs by Coassembly of Dual Anti-Cancer Nano Drugs to Inhibit DNA/RNA of Human Cancer Cells Drug Resistance”, Parana Journal of Science and Education, v. 4, n. 6, pp. 1-17, 2018

[182] A. Heidari, R. Gobato, "Ultraviolet Photoelectron Spectroscopy (UPS) and Ultraviolet-Visible (UV-Vis) Spectroscopy Comparative Study on Malignant and Benign Human Cancer Cells and Tissues with the Passage of Time under Synchrotron Radiation", Parana Journal of Science and Education, v. 4, n. 6, pp. 18-33, 2018.

[183] R. Gobato, A. Heidari, A. Mitra, "The Creation of $C_{13} H_{20}$ BeLi $i_{2}$ SeSi. The Proposal of a Bio-Inorganic Molecule, Using Ab Initio Methods for the Genesis of a Nano Membrane”, Arc Org Inorg Chem Sci 3 (4). AOICS.MS.ID.000167, 2018.

[184] R. Gobato, A. Heidari, A. Mitra, "Using the Quantum Chemistry for Genesis of a Nano Biomembrane with a Combination of the Elements Be, Li, $\mathrm{Se}, \mathrm{Si}, \mathrm{C}$ and H", ResearchGate, See discussions, stats, and author profiles for this publication at: https://www.researchgate.net/publication/326201181, 2018.

[185] R. Gobato, A. Heidari, "Using the Quantum Chemistry for Genesis of a Nano Biomembrane with a Combination of the Elements Be, Li, Se, Si, C and H", J Nanomed Res.7 (4): 241-252, 2018.

[186] A. Heidari, "Bastadins and Bastaranes-Enhanced Precatalyst Preparation Stabilization and Initiation (EPPSI) Nano Molecules”, Glob Imaging Insights, Volume 3 (4): 1-7, 2018

[187] A. Heidari, "Fucitol, Pterodactyladiene, DEAD or DEADCAT (DiEthyl AzoDiCArboxylaTe), Skatole, the NanoPutians, Thebacon, Pikachurin, Tie Fighter, Spermidine and Mirasorvone Nano Molecules Incorporation into the Nano Polymeric Matrix (NPM) by Immersion of the Nano Polymeric Modified Electrode (NPME) as Molecular Enzymes and Drug Targets for Human Cancer Cells, Tissues and Tumors Treatment under Synchrotron and Synchrocyclotron Radiations", Glob Imaging Insights, Volume 3 (4): 1-8, 2018.

[188] E. Dadvar, A. Heidari, "A Review on Separation Techniques of Graphene Oxide (GO)/Base on Hybrid Polymer Membranes for Eradication of Dyes and Oil Compounds: Recent Progress in Graphene Oxide (GO)/Base on Polymer Membranes-Related Nanotechnologies”, Clin Med Rev Case Rep 5: $228,2018$.

[189] A. Heidari, R. Gobato, "First-Time Simulation of Deoxyuridine Monophosphate (dUMP) (Deoxyuridylic Acid or Deoxyuridylate) and Vomitoxin

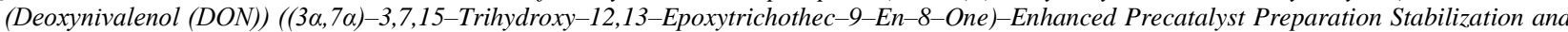
Initiation (EPPSI) Nano Molecules Incorporation into the Nano Polymeric Matrix (NPM) by Immersion of the Nano Polymeric Modified Electrode (NPME) as Molecular Enzymes and Drug Targets for Human Cancer Cells, Tissues and Tumors Treatment under Synchrotron and Synchrocyclotron Radiations", Parana Journal of Science and Education, Vol. 4, No. 6, pp. 46-67, 2018.

[190] A. Heidari, "Buckminsterfullerene (Fullerene), Bullvalene, Dickite and Josiphos Ligands Nano Molecules Incorporation into the Nano Polymeric Matrix (NPM) by Immersion of the Nano Polymeric Modified Electrode (NPME) as Molecular Enzymes and Drug Targets for Human Hematology and Thromboembolic Diseases Prevention, Diagnosis and Treatment under Synchrotron and Synchrocyclotron Radiations", Glob Imaging Insights, Volume 3 (4): 1-7, 2018

[191] A. Heidari, "Fluctuation X-Ray Scattering (FXS) and Wide-Angle X-Ray Scattering (WAXS) Comparative Study on Malignant and Benign Human Cancer Cells and Tissues under Synchrotron Radiation", Glob Imaging Insights, Volume 3 (4): 1-7, 2018.

[192] A. Heidari, “A Novel Approach to Correlation Spectroscopy (COSY), Exclusive Correlation Spectroscopy (ECOSY), Total Correlation Spectroscopy (TOCSY), Incredible Natural-Abundance Double-Quantum Transfer Experiment (INADEQUATE), Heteronuclear Single-Quantum Correlation Spectroscopy (HSQC), Heteronuclear Multiple-Bond Correlation Spectroscopy (HMBC), Nuclear Overhauser Effect Spectroscopy (NOESY) and Rotating Frame Nuclear Overhauser Effect Spectroscopy (ROESY) Comparative Study on Malignant and Benign Human Cancer Cells and Tissues under Synchrotron Radiation”, Glob Imaging Insights, Volume 3 (5): 1-9, 2018.

[193] A. Heidari, "Terphenyl-Based Reversible Receptor with Rhodamine, Rhodamine-Based Molecular Probe, Rhodamine-Based Using the Spirolactam Ring Opening, Rhodamine B with Ferrocene Substituent, Calix[4]Arene-Based Receptor, Thioether + Aniline-Derived Ligand Framework Linked 
to a Fluorescein Platform, Mercuryfluor-1 (Flourescent Probe), N,N'-Dibenzyl-1,4,10,13-Tetraraoxa-7,16-Diazacyclooctadecane and TerphenylBased Reversible Receptor with Pyrene and Quinoline as the Fluorophores-Enhanced Precatalyst Preparation Stabilization and Initiation (EPPSI) Nano Molecules”, Glob Imaging Insights, Volume 3 (5): 1-9, 2018.

[194] A. Heidari, "Small-Angle X-Ray Scattering (SAXS), Ultra-Small Angle X-Ray Scattering (USAXS), Fluctuation X-Ray Scattering (FXS), WideAngle X-Ray Scattering (WAXS), Grazing-Incidence Small-Angle X-Ray Scattering (GISAXS), Grazing-Incidence Wide-Angle X-Ray Scattering (GIWAXS), Small-Angle Neutron Scattering (SANS), Grazing-Incidence Small-Angle Neutron Scattering (GISANS), X-Ray Diffraction (XRD), Powder X-Ray Diffraction (PXRD), Wide-Angle X-Ray Diffraction (WAXD), Grazing-Incidence X-Ray Diffraction (GIXD) and Energy-Dispersive $X-$ Ray Diffraction (EDXRD) Comparative Study on Malignant and Benign Human Cancer Cells and Tissues under Synchrotron Radiation”, Glob Imaging Insights, Volume 3 (5): 1-10, 2018.

[195] A. Heidari, "Nuclear Resonant Inelastic X-Ray Scattering Spectroscopy (NRIXSS) and Nuclear Resonance Vibrational Spectroscopy (NRVS) Comparative Study on Malignant and Benign Human Cancer Cells and Tissues under Synchrotron Radiation”, Glob Imaging Insights, Volume 3 (5): 17, 2018.

[196] A. Heidari, "Small-Angle X-Ray Scattering (SAXS) and Ultra-Small Angle X-Ray Scattering (USAXS) Comparative Study on Malignant and Benign Human Cancer Cells and Tissues under Synchrotron Radiation”, Glob Imaging Insights, Volume 3 (5): 1-7, 2018.

[197] A. Heidari, "Curious Chloride $\left(\mathrm{CmCl}_{3}\right)$ and Titanic Chloride (TiCl 4 )-Enhanced Precatalyst Preparation Stabilization and Initiation (EPPSI) Nano Molecules for Cancer Treatment and Cellular Therapeutics”, J. Cancer Research and Therapeutic Interventions, Volume 1, Issue 1, Pages 01-10, 2018.

[198] R. Gobato, M. R. R. Gobato, A. Heidari, A. Mitra, "Spectroscopy and Dipole Moment of the Molecule $C_{13} H_{20} B e L i_{2} S e S i$ via Quantum Chemistry Using Ab Initio, Hartree-Fock Method in the Base Set CC-pVTZ and 6-311G**(3df, 3pd)”, Arc Org Inorg Chem Sci 3 (5), Pages 402-409, 2018.

[199] A. Heidari, " $C_{60}$ and $C_{70}$ Encapsulating Carbon Nanotubes Incorporation into the Nano Polymeric Matrix (NPM) by Immersion of the Nano Polymeric Modified Electrode (NPME) as Molecular Enzymes and Drug Targets for Human Cancer Cells, Tissues and Tumors Treatment under Synchrotron and Synchrocyclotron Radiations", Integr Mol Med, Volume 5 (3): 1-8, 2018.

[200] A. Heidari, "Two-Dimensional (2D) ${ }^{1} \mathrm{H}$ or Proton NMR, ${ }^{13} \mathrm{C} N M R,{ }^{15} \mathrm{~N} N M R$ and ${ }^{31} \mathrm{P}$ NMR Spectroscopy Comparative Study on Malignant and Benign Human Cancer Cells and Tissues under Synchrotron Radiation with the Passage of Time”, Glob Imaging Insights, Volume 3 (6): 1-8, 2018.

[201] A. Heidari, "FT-Raman Spectroscopy, Coherent Anti-Stokes Raman Spectroscopy (CARS) and Raman Optical Activity Spectroscopy (ROAS) Comparative Study on Malignant and Benign Human Cancer Cells and Tissues with the Passage of Time under Synchrotron Radiation”, Glob Imaging Insights, Volume 3 (6): 1-8, 2018.

[202] A. Heidari, “A Modern and Comprehensive Investigation of Inelastic Electron Tunneling Spectroscopy (IETS) and Scanning Tunneling Spectroscopy on Malignant and Benign Human Cancer Cells, Tissues and Tumors through Optimizing Synchrotron Microbeam Radiotherapy for Human Cancer Treatments and Diagnostics: An Experimental Biospectroscopic Comparative Study”, Glob Imaging Insights, Volume 3 (6): 1-8, 2018.

[203] A. Heidari, “A Hypertension Approach to Thermal Infrared Spectroscopy and Photothermal Infrared Spectroscopy Comparative Study on Malignant and Benign Human Cancer Cells and Tissues under Synchrotron Radiation with the Passage of Time”, Glob Imaging Insights, Volume 3 (6): 1-8, 2018.

[204] A. Heidari, "Incredible Natural-Abundance Double-Quantum Transfer Experiment (INADEQUATE), Nuclear Overhauser Effect Spectroscopy (NOESY) and Rotating Frame Nuclear Overhauser Effect Spectroscopy (ROESY) Comparative Study on Malignant and Benign Human Cancer Cells and Tissues under Synchrotron Radiation”, Glob Imaging Insights, Volume 3 (6): 1-8, 2018.

[205] A. Heidari, "2-Amino-9-((1S, 3R, 4R)-4-Hydroxy-3-(Hydroxymethyl)-2-Methylenecyclopentyl)-1H-Purin-6(9H)-One, 2-Amino-9-((1R, 3R, 4R)-4-Hydroxy-3-(Hydroxymethyl)-2-Methylenecyclopentyl $)-1 H-P$ urin-6(9H)-One, 2-Amino-9- $((1 R, 3 R, 4 S)-4-H y d r o x y-3-(H y d r o x y m e t h y l)-$ 2-Methylenecyclopentyl)-1H-Purin-6(9H)-One and 2-Amino-9-((1S, 3R, 4S)-4-Hydroxy-3-(Hydroxymethyl)-2-Methylenecyclopentyl)-1H-Purin-6(9H)-One-Enhanced Precatalyst Preparation Stabilization and Initiation Nano Molecules”, Glob Imaging Insights, Volume 3 (6): 1-9, 2018.

[206] R. Gobato, M. R. R. Gobato, A. Heidari, A. Mitra, "Spectroscopy and Dipole Moment of the Molecule $\mathrm{C}_{13} \mathrm{H}_{20} \mathrm{BeLi}_{2} \mathrm{SeSi}$ via Quantum Chemistry Using Ab Initio, Hartree-Fock Method in the Base Set CC-pVTZ and 6-311G**(3df, 3pd) ', American Journal of Quantum Chemistry and Molecular Spectroscopy, Vol. 2, No. 1, pp. 9-17, 2018.

[207] A. Heidari, "Production of Electrochemiluminescence (ECL) Biosensor Using Os-Pd/HfC Nanocomposites for Detecting and Tracking of Human Gastroenterological Cancer Cells, Tissues and Tumors", Int J Med Nano Res 5: 1, 022-034, 2018.

[208] A. Heidari, "Enhancing the Raman Scattering for Diagnosis and Treatment of Human Cancer Cells, Tissues and Tumors Using Cadmium Oxide (CdO) Nanoparticles", J Toxicol Risk Assess 4: 1, 012-025, 2018.

[209] A. Heidari, "Human Malignant and Benign Human Cancer Cells and Tissues Biospectroscopic Analysis under Synchrotron Radiation Using AntiCancer Nano Drugs Delivery”, Integr Mol Med, Volume 5 (5): 1-13, 2018.

[210] A. Heidari, "Analogous Nano Compounds of the Form $M\left(C_{8} H_{8}\right)_{2}$ Exist for $M=(N d, T b, P u, P a, N p$, Th, and Yb)-Enhanced Precatalyst Preparation Stabilization and Initiation (EPPSI) Nano Molecules”, Integr Mol Med, Volume 5 (5): 1-8, 2018.

[211] A. Heidari, "Hadron Spectroscopy, Baryon Spectroscopy and Meson Spectroscopy Comparative Study on Malignant and Benign Human Cancer Cells and Tissues under Synchrotron Radiation”, Integr Mol Med, Volume 5 (5): 1-8, 2018.

[212] R. Gobato, M. R. R. Gobato, A. Heidari, "Raman Spectroscopy Study of the Nano Molecule $C_{13} H_{20} B e L i_{2} S e S i$ Using ab initio and Hartree-Fock Methods in the Basis Set CC-pVTZ and 6-311G** (3df, 3pd)", International Journal of Advanced Engineering and Science, Volume 7, Number 1, Pages 14-35, 2019.

[213] A. Heidari, R. Gobato, "Evaluating the Effect of Anti-Cancer Nano Drugs Dosage and Reduced Leukemia and Polycythemia Vera Levels on Trend of the Human Blood and Bone Marrow Cancers under Synchrotron Radiation”, Trends in Res, Volume 2 (1): 1-8, 2019.

[214] A. Heidari, R. Gobato, "Assessing the Variety of Synchrotron, Synchrocyclotron and LASER Radiations and Their Roles and Applications in Human Cancer Cells, Tissues and Tumors Diagnosis and Treatment”, Trends in Res, Volume 2 (1): 1-8, 2019.

[215] A. Heidari, R. Gobato, "Pros and Cons Controversy on Malignant Human Cancer Cells, Tissues and Tumors Transformation Process to Benign Human Cancer Cells, Tissues and Tumors”, Trends in Res, Volume 2 (1): 1-8, 2019.

[216] A. Heidari, R. Gobato, "Three-Dimensional (3D) Simulations of Human Cancer Cells, Tissues and Tumors for Using in Human Cancer Cells, Tissues and Tumors Diagnosis and Treatment as a Powerful Tool in Human Cancer Cells, Tissues and Tumors Research and Anti-Cancer Nano Drugs Sensitivity and Delivery Area Discovery and Evaluation", Trends in Res, Volume 2 (1): 1-8, 2019.

[217] A. Heidari, R. Gobato, "Investigation of Energy Production by Synchrotron, Synchrocyclotron and LASER Radiations in Human Cancer Cells, Tissues and Tumors and Evaluation of Their Effective on Human Cancer Cells, Tissues and Tumors Treatment Trend", Trends in Res, Volume 2 (1): $1-8,2019$

[218] A. Heidari, R. Gobato, "High-Resolution Mapping of DNA/RNA Hypermethylation and Hypomethylation Process in Human Cancer Cells, Tissues and Tumors under Synchrotron Radiation”, Trends in Res, Volume 2 (2): 1-9, 2019.

[219] A. Heidari, “A Novel and Comprehensive Study on Manufacturing and Fabrication Nanoparticles Methods and Techniques for Processing Cadmium Oxide (CdO) Nanoparticles Colloidal Solution”, Glob Imaging Insights, Volume 4 (1): 1-8, 2019.

[220] A. Heidari, "A Combined Experimental and Computational Study on the Catalytic Effect of Aluminum Nitride Nanocrystal (AlN) on the Polymerization of Benzene, Naphthalene, Anthracene, Phenanthrene, Chrysene and Tetracene”, Glob Imaging Insights, Volume 4 (1): 1-8, 2019.

[221] A. Heidari, "Novel Experimental and Three-Dimensional (3D) Multiphysics Computational Framework of Michaelis-Menten Kinetics for Catalyst Processes Innovation, Characterization and Carrier Applications”, Glob Imaging Insights, Volume 4 (1): 1-8, 2019.

[222] A. Heidari, "The Hydrolysis Constants of Copper (I) $\left(\mathrm{Cu}^{+}\right)$and Copper (II) (Cu $\left.{ }^{2+}\right)$ in Aqueous Solution as a Function of pH Using a Combination of pH Measurement and Biospectroscopic Methods and Techniques”, Glob Imaging Insights, Volume 4 (1): 1-8, 2019. 
[223] A. Heidari, "Vibrational Biospectroscopic Study of Ginormous Virus-Sized Macromolecule and Polypeptide Macromolecule as Mega Macromolecules Using Attenuated Total Reflectance-Fourier Transform Infrared (ATR-FTIR) Spectroscopy and Mathematica 11.3”, Glob Imaging Insights, Volume 4 (1): 1-8, 2019.

[224] A. Heidari, “Three-Dimensional (3D) Imaging Spectroscopy of Carcinoma, Sarcoma, Leukemia, Lymphoma, Multiple Myeloma, Melanoma, Brain and Spinal Cord Tumors, Germ Cell Tumors, Neuroendocrine Tumors and Carcinoid Tumors under Synchrotron Radiation”, Glob Imaging Insights, Volume 4 (1): 1-9, 2019.

[225] R. Gobato, M. R. R. Gobato, A. Heidari, “Storm Vortex in the Center of Paraná State on June 6, 2017: A Case Study”, Sumerianz Journal of Scientific Research, Vol. 2, No. 2, Pages 24-31, 2019.

[226] R. Gobato, M. R. R. Gobato, A. Heidari, “Attenuated Total Reflection-Fourier Transform Infrared (ATR-FTIR) Spectroscopy Study of the Nano Molecule $\mathrm{C}_{13} \mathrm{H}_{20} \mathrm{BeLi}_{2} \mathrm{SeSi}$ Using ab initio and Hartree-Fock Methods in the Basis Set RHF/CC-pVTZ and RHF/6-311G** (3df, 3pd): An Experimental Challenge to Chemists", Chemistry Reports, Vol. 2, No. 1, Pages 1-26, 2019.

[227] A. Heidari, “Three-Dimensional (3D) Imaging Spectroscopy of Carcinoma, Sarcoma, Leukemia, Lymphoma, Multiple Myeloma, Melanoma, Brain and Spinal Cord Tumors, Germ Cell Tumors, Neuroendocrine Tumors and Carcinoid Tumors under Synchrocyclotron Radiation”, Res Adv Biomed Sci Technol 1 (1): 01-17, 2019.

[228] R. Gobato, M. R. R. Gobato, A. Heidari, A. Mitra, "New Nano-Molecule Kurumi-C ${ }_{13} \mathrm{H}_{20} \mathrm{BeLi}_{2} \mathrm{SeSi} / \mathrm{C}_{13} \mathrm{H}_{19} \mathrm{BeLi} \mathrm{L}_{2} \mathrm{SeSi}$, and Raman Spectroscopy Using ab initio, Hartree-Fock Method in the Base Set CC-pVTZ and 6-311G** (3df, 3pd)", J Anal Pharm Res. 8 (1): 1-6, 2019.

[229] A. Heidari, J. Esposito, A. Caissutti, “The Importance of Attenuated Total Reflectance Fourier Transform Infrared (ATR-FTIR) and Raman Biospectroscopy of Single-Walled Carbon Nanotubes (SWCNT) and Multi-Walled Carbon Nanotubes (MWCNT) in Interpreting Infrared and Raman Spectra of Human Cancer Cells, Tissues and Tumors", Oncogen 2 (2): 1-21, 2019.

[230] A. Heidari, "Mechanism of Action and Their Side Effects at a Glance Prevention, Treatment and Management of Immune System and Human Cancer Nano Chemotherapy”, Nanosci Technol 6 (1): 1-4, 2019.

[231] A. Heidari, J. Esposito, A. Caissutti, “The Quantum Entanglement Dynamics Induced by Non-Linear Interaction between a Moving Nano Molecule and a Two-Mode Field with Two-Photon Transitions Using Reduced Von Neumann Entropy and Jaynes-Cummings Model for Human Cancer Cells, Tissues and Tumors Diagnosis", Int J Crit Care Emerg Med 5 (2): 071-084, 2019.

[232] A. Heidari, J. Esposito, A. Caissutti, "Palytoxin Time-Resolved Absorption and Resonance FT-IR and Raman Biospectroscopy and Density Functional Theory (DFT) Investigation of Vibronic-Mode Coupling Structure in Vibrational Spectra Analysis”, J Pharm Drug Res, 3 (1): 150-170, 2019.

[233] A. Heidari, J. Esposito, A. Caissutti, "Aplysiatoxin Time-Resolved Absorption and Resonance FT-IR and Raman Biospectroscopy and Density Functional Theory (DFT) Investigation of Vibronic-Mode Coupling Structure in Vibrational Spectra Analysis”, J Chem Sci Eng, 2 (2): 70-89, 2019.

[234] R. Gobato, M. R. R. Gobato, A. Heidari, A. Mitra, "Spectroscopy and Dipole Moment of the Molecule $C_{13} \mathrm{H}_{20}$ BeLi $i_{2}$ SeSi via Quantum Chemistry Using Ab initio, Hartree-Fock Method in the Base Set CC-pVTZ and 6-311G** (3df, 3pd)”, American Journal of Quantum Chemistry and Molecular Spectroscopy, 2 (1): 9-17, 2018.

[235] A. Heidari, J. Esposito, A. Caissutti, "Cyanotoxin Time-Resolved Absorption and Resonance FT-IR and Raman Biospectroscopy and Density Functional Theory (DFT) Investigation of Vibronic-Mode Coupling Structure in Vibrational Spectra Analysis”, Br J Med Health Res. 6 (04): 2160, 2019.

[236] A. Heidari, "Potential and Theranostics Applications of Novel Anti-Cancer Nano Drugs Delivery Systems in Preparing for Clinical Trials of Synchrotron Microbeam Radiation Therapy (SMRT) and Synchrotron Stereotactic Radiotherapy (SSRT) for Treatment of Human Cancer Cells, Tissues and Tumors Using Image Guided Synchrotron Radiotherapy (IGSR)”, Ann Nanosci Nanotechnol. 3 (1): 1006-1019, 2019.

[237] A. Heidari, J. Esposito, A. Caissutti, "Study of Anti-Cancer Properties of Thin Layers of Cadmium Oxide (CdO) Nanostructure”, Int J Analyt Bioanalyt Methods 1 (1): 003-022, 2019.

[238] A. Heidari, J. Esposito, A. Caissutti, "Alpha-Conotoxin, Omega-Conotoxin and Mu-Conotoxin Time-Resolved Absorption and Resonance FT-IR and Raman Biospectroscopy and Density Functional Theory (DFT) Investigation of Vibronic-Mode Coupling Structure in Vibrational Spectra Analysis", International Journal of Advanced Chemistry, 7 (1) 52-66, 2019.

[239] A. Heidari, "Clinical and Medical Pros and Cons of Human Cancer Cells' Enzymotherapy, Immunotherapy, Chemotherapy, Radiotherapy, Hormone Therapy and Targeted Therapy Process under Synchrotron Radiation: A Case Study on Mechanism of Action and Their Side Effects", Parana Journal of Science and Education (PJSE)-v. 5, n. 3, (1-23) May 2, 2019.

[240] A. Heidari, “The Importance of the Power in CMOS Inverter Circuit of Synchrotron and Synchrocyclotron Radiations Using 50 (nm) and 100 (nm) Technologies and Reducing the Voltage of Power Supply", Radiother Oncol Int. 1 (1): 1002-1015, 2019.

[241] A. Heidari, J. Esposito, A. Caissutti, "The Importance of Quantum Hydrodynamics (OHD) Approach to Single-Walled Carbon Nanotubes (SWCNT) and Multi-Walled Carbon Nanotubes (MWCNT) in Genetic Science”, SCIOL Genet Sci. 2 (1): 113-129, 2019.

[242] A. Heidari, J. Esposito, A. Caissutti, “Anatoxin-a and Anatoxin-a(s) Time-Resolved Absorption and Resonance FT-IR and Raman Biospectroscopy and Density Functional Theory (DFT) Investigation of Vibronic-Mode Coupling Structure in Vibrational Spectra Analysis", Saudi J Biomed Res, 4 (4): 174-194, 2019.

[243] R. Gobato, M. R. R. Gobato, A. Heidari, "Evidence of Tornado Storm Hit the Counties of Rio Branco do Ivaí and Rosario de Ivaí, Southern Brazil”, Sci Lett, 7 (1): 32-40, 2019.

[244] M. Jeyaraj, V. Mahalingam, A. Indhuleka, P. Sennu, M. S. Ho, A. Heidari, "Chemical Analysis of Surface Water Quality of River Noyyal Connected Tank in Tirupur District, Tamil Nadu, India”, Water and Energy International, Volume 62r, Issue 1, pp. 63-68, 2019.

[245] A. Heidari, J. Esposito, A. Caissutti, "6-Methoxy-8-[[6-Methoxy-8-[[6-Methoxy-2-Methyl-1-(2-Methylpropyl)-3,4-Dihydro-1H-Isoquinolin7-yl]Oxy]-2-Methyl-1-(2-Methylpropyl)-3,4-Dihydro-1H-Isoquinolin-7-yllOxy]-2-Methyl-1-(2-Methylpropyl)-3,4-Dihydro-1H-Isoquinolin-7-ol Time-Resolved Absorption and Resonance FT-IR and Raman Biospectroscopy and Density Functional Theory (DFT) Investigation of Vibronic-Mode Coupling Structure in Vibrational Spectra Analysis", J. Adv. Phys. Chem., Volume 1, Issue 1, pp. 1-6, 2019.

[246] A. Heidari, J. Esposito, A. Caissutti, "Shiga Toxin and Shiga-Like Toxin (SLT) Time-Resolved Absorption and Resonance FT-IR and Raman Biospectroscopy and Density Functional Theory (DFT) Investigation of Vibronic-Mode Coupling Structure in Vibrational Spectra Analysis", Annal Biostat \& Biomed Appli. 2 (3): 1-4, 2019.

[247] A. Heidari, J. Esposito, A. Caissutti, “Alpha-Bungarotoxin, Beta-Bungarotoxin and Kappa-Bungarotoxin Time-Resolved Absorption and Resonance FT-IR and Raman Biospectroscopy and Density Functional Theory (DFT) Investigation of Vibronic-Mode Coupling Structure in Vibrational Spectra Analysis", Archives of Pharmacology and Pharmaceutical Sciences, ReDelve, Volume 2019, Issue 01, pp. 1-24, 2019.

[248] A. Heidari, J. Esposito, A. Caissutti, "Okadaic Acid Time-Resolved Absorption and Resonance FT-IR and Raman Biospectroscopy and Density Functional Theory (DFT) Investigation of Vibronic-Mode Coupling Structure in Vibrational Spectra Analysis”, Int J Analyt Bioanalyt Methods 1 (1): 1-19, 2019.

[249] A. Heidari, "Investigation of the Processes of Absorption, Distribution, Metabolism and Elimination (ADME) as Vital and Important Factors for Modulating Drug Action and Toxicity", Open Access J Oncol, 2 (1): 180010-180012, 2019.

[250] A. Heidari, J. Esposito, A. Caissutti, "Pertussis Toxin Time-Resolved Absorption and Resonance FT-IR and Raman Biospectroscopy and Density Functional Theory (DFT) Investigation of Vibronic-Mode Coupling Structure in Vibrational Spectra Analysis", Chemistry Reports, Vol. 1 Iss. 2, Pages 1-5, 2019.

[251] R. Gobato, M. R. R. Gobato, A. Heidari, “Rhodochrosite as Crystal Oscillator”, Am J Biomed Sci \& Res. 3 (2), $187,2019$.

[252] A. Heidari, J. Esposito, A. Caissutti, "Tetrodotoxin (TTX) Time-Resolved Absorption and Resonance FT-IR and Raman Biospectroscopy and Density Functional Theory (DFT) Investigation of Vibronic-Mode Coupling Structure in Vibrational Spectra Analysis”, Journal of New Developments in Chemistry, Volume No: 2, Issue No: 3, Page Numbers 26-48, 2019. 
[253] A. Heidari, J. Esposito, A. Caissutti, “The Importance of Analysis of Vibronic-Mode Coupling Structure in Vibrational Spectra of Supramolecular Aggregates of $\left(C A^{*} M\right)$ Cyanuric Acid $(C A)$ and Melamine $(M)$ beyond the Franck-Condon Approximation”, Journal of Clinical and Medical Images, 2 (2): 1-20, 2019.

[254] A. Heidari, J. Esposito, A. Caissutti, "Microcystin-LR Time-Resolved Absorption and Resonance FT-IR and Raman Biospectroscopy and Density Functional Theory (DFT) Investigation of Vibronic-Mode Coupling Structure in Vibrational Spectra Analysis”, Malaysian Journal of Chemistry, Vol. 21 (1), 70-95, 2019.

[255] A. Heidari, J. Esposito, A. Caissutti, “Botulinum Toxin Time-Resolved Absorption and Resonance FT-IR and Raman Biospectroscopy and Density Functional Theory (DFT) Investigation of Vibronic-Mode Coupling Structure in Vibrational Spectra Analysis", Journal of Mechanical Design and Vibration, vol. 7, no. 1: 1-15, 2019.

[256] A. Heidari, J. Esposito, A. Caissutti, "Domoic Acid (DA) Time-Resolved Absorption and Resonance FT-IR and Raman Biospectroscopy and Density Functional Theory (DFT) Investigation of Vibronic-Mode Coupling Structure in Vibrational Spectra Analysis", Cientific Clinical Oncology Journal 1. 2: 03-07, 2019.

[257] A. Heidari, J. Esposito, A. Caissutti, "Surugatoxin (SGTX) Time-Resolved Absorption and Resonance FT-IR and Raman Biospectroscopy and Density Functional Theory (DFT) Investigation of Vibronic-Mode Coupling Structure in Vibrational Spectra Analysis", Cientific Clinical Oncology Journal 1. 2: 14-18, 2019.

[258] A. Heidari, J. Esposito, A. Caissutti, "Decarbamoylsaxitoxin Time-Resolved Absorption and Resonance FT-IR and Raman Biospectroscopy and Density Functional Theory (DFT) Investigation of Vibronic-Mode Coupling Structure in Vibrational Spectra Analysis", Cientific Clinical Oncology Journal 1. 2: 19-23, 2019.

[259] A. Heidari, J. Esposito, A. Caissutti, "Gonyautoxin (GTX) Time-Resolved Absorption and Resonance FT-IR and Raman Biospectroscopy and Density Functional Theory (DFT) Investigation of Vibronic-Mode Coupling Structure in Vibrational Spectra Analysis", Cientific Clinical Oncology Journal 1. 2: 24-28, 2019.

[260] A. Heidari, J. Esposito, A. Caissutti, "Hislrionicotoxin Time-Resolved Absorption and Resonance FT-IR and Raman Biospectroscopy and Density Functional Theory (DFT) Investigation of Vibronic-Mode Coupling Structure in Vibrational Spectra Analysis", Cientific Drug Delivery Research 1. 1: $01-06,2019$.

[261] A. Heidari, J. Esposito, A. Caissutti, "Dihydrokainic Acid Time-Resolved Absorption and Resonance FT-IR and Raman Biospectroscopy and Density Functional Theory (DFT) Investigation of Vibronic-Mode Coupling Structure in Vibrational Spectra Analysis”, Cientific Drug Delivery Research 1. 1: 07-12, 2019.

[262] A. Heidari, J. Esposito, A. Caissutti, “Aflatoxin B1 (AFB1), B2 (AFB2), G1 (AFG1), G2 (AFG2), M1 (AFM1), M2 (AFM2), Q1 (AFQ1) and P1 (AFP1) Time-Resolved Absorption and Resonance FT-IR and Raman Biospectroscopy and Density Functional Theory (DFT) Investigation of Vibronic-Mode Coupling Structure in Vibrational Spectra Analysis", Cientific Drug Delivery Research 1. 1: 25-32, 2019.

[263] A. Heidari, J. Esposito, A. Caissutti, "Mycotoxin Time-Resolved Absorption and Resonance FT-IR and Raman Biospectroscopy and Density Functional Theory (DFT) Investigation of Vibronic-Mode Coupling Structure in Vibrational Spectra Analysis”, Cientific Drug Delivery Research 1. 1: $13-18,2019$.

[264] A. Heidari, J. Esposito, A. Caissutti, “Bufotoxin Time-Resolved Absorption and Resonance FT-IR and Raman Biospectroscopy and Density Functional Theory (DFT) Investigation of Vibronic-Mode Coupling Structure in Vibrational Spectra Analysis”, Cientific Drug Delivery Research 1. 1: $19-24,2019$.

[265] A. Heidari, J. Esposito, A. Caissutti, "Kainic Acid (Kainite) Time-Resolved Absorption and Resonance FT-IR and Raman Biospectroscopy and Density Functional Theory (DFT) Investigation of Vibronic-Mode Coupling Structure in Vibrational Spectra Analysis”, Cientific Journal of Neurology 1. 2: 02-07, 2019.

[266] A. Heidari, J. Esposito, A. Caissutti, "Nereistoxin Time-Resolved Absorption and Resonance FT-IR and Raman Biospectroscopy and Density Functional Theory (DFT) Investigation of Vibronic-Mode Coupling Structure in Vibrational Spectra Analysis”, Cientific Journal of Neurology 1. 2: 19-24, 2019.

[267] A. Heidari, J. Esposito, A. Caissutti, "Spider Toxin and Raventoxin Time-Resolved Absorption and Resonance FT-IR and Raman Biospectroscopy and Density Functional Theory (DFT) Investigation of Vibronic-Mode Coupling Structure in Vibrational Spectra Analysis”, Parana Journal of Science and Education. Vol. 5, No. 4, pp. 1-28, 2019.

[268] A. Heidari, J. Esposito, A. Caissutti, "Ochratoxin A, Ochratoxin B, Ochratoxin C, Ochratoxin a and Ochratoxin TA Time-Resolved Absorption and Resonance FT-IR and Raman Biospectroscopy and Density Functional Theory (DFT) Investigation of Vibronic-Mode Coupling Structure in Vibrational Spectra Analysis”, Cientific Drug Delivery Research 1. 2: 03-10, 2019.

[269] A. Heidari, J. Esposito, A. Caissutti, "Brevetoxin A and B Time-Resolved Absorption and Resonance FT-IR and Raman Biospectroscopy and Density Functional Theory (DFT) Investigation of Vibronic-Mode Coupling Structure in Vibrational Spectra Analysis”, Cientific Drug Delivery Research 1. 2: 11-16, 2019.

[270] A. Heidari, J. Esposito, A. Caissutti, "Lyngbyatoxin-a Time-Resolved Absorption and Resonance FT-IR and Raman Biospectroscopy and Density Functional Theory (DFT) Investigation of Vibronic-Mode Coupling Structure in Vibrational Spectra Analysis”, Cientific Drug Delivery Research 1. 2: 23-28, 2019.

[271] A. Heidari, J. Esposito, A. Caissutti, "Balraechotoxin (BTX) Time-Resolved Absorption and Resonance FT-IR and Raman Biospectroscopy and Density Functional Theory (DFT) Investigation of Vibronic-Mode Coupling Structure in Vibrational Spectra Analysis”, Cientific Journal of Neurology 1. 3: 01-05, 2019.

[272] A. Heidari, J. Esposito, A. Caissutti, "Hanatoxin Time-Resolved Absorption and Resonance FT-IR and Raman Biospectroscopy and Density Functional Theory (DFT) Investigation of Vibronic-Mode Coupling Structure in Vibrational Spectra Analysis”, Int. J. Pharm. Sci. Rev. Res., 57 (1), Pages: 21-32, 2019

[273] A. Heidari, J. Esposito, A. Caissutti, "Neurotoxin and Alpha-Neurotoxin Time-Resolved Absorption and Resonance FT-IR and Raman Biospectroscopy and Density Functional Theory (DFT) Investigation of Vibronic-Mode Coupling Structure in Vibrational Spectra Analysis”, J Biomed Sci \& Res. 3 (6), 550-563, 2019.

[274] A. Heidari, J. Esposito, A. Caissutti, “Antillatoxin (ATX) Time-Resolved Absorption and Resonance FT-IR and Raman Biospectroscopy and Density Functional Theory (DFT) Investigation of Vibronic-Mode Coupling Structure”, American Journal of Optics and Photonics. Vol. 7, No. 1, pp. 1827, 2019.

[275] R. Gobato, M. R. R. Gobato, A. Heidari, “Calculation by UFF Method of Frequencies and Vibrational Temperatures of the Unit Cell of the Rhodochrosite Crystal”, International Journal of Advanced Chemistry, 7 (2) 77-81, 2019.

[276] A. Heidari, J. Esposito, A. Caissutti, "Analysis of Vibronic-Mode Coupling Structure in Vibrational Spectra of Fuzeon as a 36 Amino Acid Peptide for HIV Therapy beyond the Multi-Dimensional Franck-Condon Integrals Approximation”, International Journal of Advanced Chemistry, 7 (2) 8296, 2019.

[277] A. Heidari, J. Esposito, A. Caissutti, "Debromoaplysiatoxin Time-Resolved Absorption and Resonance FT-IR and Raman Biospectroscopy and Density Functional Theory (DFT) Investigation of Vibronic-Mode Coupling Structure in Vibrational Spectra Analysis”, Applied Chemistry, 2 (1) 17-54, 2019.

[278] A. Heidari, J. Esposito, A. Caissutti, "Enterotoxin Time-Resolved Absorption and Resonance FT-IR and Raman Biospectroscopy and Density Functional Theory (DFT) Investigation of Vibronic-Mode Coupling Structure in Vibrational Spectra Analysis”, JRL J Sci Technol. vol1-iss2: jst1001, 1-16, 2019.

[279] R. Gobato, M. R. R. Gobato, A. Heidari, A. Mitra, “Rhodochrosite Optical Indicatrix”, Peer Res Nest. 1 (3) 1-2, 2019. 
[280] A. Heidari, J. Esposito, A. Caissutti, "Anthrax Toxin Time-Resolved Absorption and Resonance FT-IR and Raman Biospectroscopy and Density Functional Theory (DFT) Investigation of Vibronic-Mode Coupling Structure in Vibrational Spectra Analysis”, Research \& Reviews: Journal of Computational Biology. 8 (2): 23-51, 2019.

[281] A. Heidari, J. Esposito, A. Caissutti, "Kalkitoxin Time-Resolved Absorption and Resonance FT-IR and Raman Biospectroscopy and Density Functional Theory (DFT) Investigation of Vibronic-Mode Coupling Structure in Vibrational Spectra Analysis”, Can J Biomed Res \& Tech. 2 (1): 1-21, 2019.

[282] A. Heidari, J. Esposito, A. Caissutti, "Neosaxitoxin Time-Resolved Absorption and Resonance FT-IR and Raman Biospectroscopy and Density Functional Theory (DFT) Investigation of Vibronic-Mode Coupling Structure in Vibrational Spectra Analysis”, Clin Case Studie Rep, Volume 2 (3): 1-14, 2019.

[283] A. Heidari, J. Esposito, A. Caissutti, "6-Methoxy-8-[[6-Methoxy-8-[[6-Methoxy-2-Methyl-1-(2-Methylpropyl)-3,4-Dihydro-1H-Isoquinolin7-yl]Oxy]-2-Methyl-1-(2-Methylpropyl)-3,4-Dihydro-1H-Isoquinolin-7-yl]Oxy]-2-Methyl-1-(2-Methylpropyl)-3,4-Dihydro-1H-Isoquinolin-7-ol Time-Resolved Absorption and Resonance FT-IR and Raman Biospectroscopy and Density Functional Theory (DFT) Investigation of Vibronic-Mode Coupling Structure in Vibrational Spectra Analysis”, Clin Case Studie Rep, Volume 2 (3): 1-14, 2019.

[284] A. Heidari, “Comparison of Synchrotron Radiation and Synchrocyclotron Radiation Performance in Monitoring of Human Cancer Cells, Tissues and Tumors", Clin Case Studie Rep, Volume 2 (3): 1-12, 2019.

[285] A. Heidari, J. Esposito, A. Caissutti, "Kalkitoxin Time-Resolved Absorption and Resonance FT-IR and Raman Biospectroscopy and Density Functional Theory (DFT) Investigation of Vibronic-Mode Coupling Structure in Vibrational Spectra Analysis”, Clin Case Studie Rep, Volume 2 (3): 1$14,2019$.

[286] A. Heidari, J. Esposito, A. Caissutti, “Diphtheria Toxin Time-Resolved Absorption and Resonance FT-IR and Raman Biospectroscopy and Density Functional Theory (DFT) Investigation of Vibronic-Mode Coupling Structure in Vibrational Spectra Analysis: A Spectroscopic Study on an AntiCancer Drug”, Clin Case Studie Rep, Volume 2 (3): 1-14, 2019.

[287] A. Heidari, J. Esposito, A. Caissutti, "Symbiodinolide Time-Resolved Absorption and Resonance FT-IR and Raman Biospectroscopy and Density Functional Theory (DFT) Investigation of Vibronic-Mode Coupling Structure in Vibrational Spectra Analysis”, Clin Case Studie Rep, Volume 2 (3): 1-14, 2019.

[288] A. Heidari, J. Esposito, A. Caissutti, "Saxitoxin Time-Resolved Absorption and Resonance FT-IR and Raman Biospectroscopy and Density Functional Theory Investigation of Vibronic-Mode Coupling Structure in Vibrational Spectra Analysis”, Am J Exp Clin Res. 6 (4): $364-377,2019$.

[289] R. Gobato, M. R. R. Gobato, A. Heidari, A. Mitra, "Hartree-Fock Methods Analysis Protonated Rhodochrosite Crystal and Potential in the Elimination of Cancer Cells through Synchrotron Radiation”, Vol. 5, No. 3, pp. 27-36, 2019.

[290] R. Gobato, I. K. K. Dosh, A. Heidari, A. Mitra, M. R. R. Gobato, "Perspectives on the Elimination of Cancer Cells Using Rhodochrosite Crystal Through Synchrotron Radiation, and Absorption the Tumoral and Non-Tumoral Tissues”, Arch Biomed Eng \& Biotechnol. 3 (2): 1-2, 2019.

[291] R. Gobato, M. R. R. Gobato, A. Heidari, A. Mitra, "Unrestricted Hartree-Fock Computational Simulation in a Protonated Rhodochrosite Crystal", Phys Astron Int J. 3 (6):220-228, 2019.

[292] A. Heidari, K. Schmitt, M. Henderson, E. Besana, "Perspectives on Sub-Nanometer Level of Electronic Structure of the Synchrotron with Mendelevium Nanoparticles for Elimination of Human Cancer Cells, Tissues and Tumors Treatment Using Mathematica 12.0”, Journal of Energy Conservation, Volume 1, Issue 2, Pages 46-73, 2019.

[293] A. Heidari, K. Schmitt, M. Henderson, E. Besana, "Simulation of Interaction of Synchrotron Radiation Emission as a Function of the Beam Energy and Bohrium Nanoparticles Using 3D Finite Element Method (FEM) as an Optothermal Human Cancer Cells, Tissues and Tumors Treatment", Current Research in Biochemistry and Molecular Biology, 1 (1), 17-44, 2019.

[294] A. Heidari, K. Schmitt, M. Henderson, E. Besana, "Investigation of Interaction between Synchrotron Radiation and Thulium Nanoparticles for Human Cancer Cells, Tissues and Tumors Treatment”, European Journal of Scientific Exploration, Volume 2, Issue 3, Pages 1-8, 2019.

[295] A. Heidari, K. Schmitt, M. Henderson, E. Besana, "The Effectiveness of the Treatment Human Cancer Cells, Tissues and Tumors Using Darmstadtium Nanoparticles and Synchrotron Radiation”, International Journal of Advanced Engineering and Science, Volume 9, Number 1, Pages 9-39, 2020.

[296] A. Heidari, K. Schmitt, M. Henderson, E. Besana, "Using 3D Finite Element Method (FEM) as an Optothermal Human Cancer Cells, Tissues and Tumors Treatment in Simulation of Interaction of Synchrotron Radiation Emission as a Function of the Beam Energy and Uranium Nanoparticles”, Nano Prog., 1 (2), 1-6, 2019.

[297] A. Heidari, K. Schmitt, M. Henderson, E. Besana, “A New Approach to Interaction between Beam Energy and Erbium Nanoparticles”, Saudi J Biomed Res, 4 (11): 372-396, 2019.

[298] A. Heidari, K. Schmitt, M. Henderson, E. Besana, “Consideration of Energy Functions and Wave Functions of the Synchrotron Radiation and Samarium Nanoparticles Interaction During Human Cancer Cells, Tissues and Tumors Treatment Process”, Sci. Int. (Lahore), 31 (6), 885-908, 2019.

[299] A. Heidari, K. Schmitt, M. Henderson, E. Besana, “An Outlook on Optothermal Human Cancer Cells, Tissues and Tumors Treatment Using Lanthanum Nanoparticles under Synchrotron Radiation”, Journal of Materials Physics and Chemistry, Vol. 7, No. 1, 29-45, 2019.

[300] A. Heidari, K. Schmitt, M. Henderson, E. Besana, "Effectiveness of Einsteinium Nanoparticles in Optothermal Human Cancer Cells, Tissues and Tumors Treatment under Synchrotron Radiation”, Journal of Analytical Oncology, 8, 1, 43-62, 2019.

[301] A. Heidari, K. Schmitt, M. Henderson, E. Besana, "Study of Relation between Synchrotron Radiation and Dubnium Nanoparticles in Human Cancer Cells, Tissues and Tumors Treatment Process”, Int. Res. J. Applied Sci., Volume 1, Number 4, Pages 1-20, 2019.

[302] Amir Shahram Yousefi Kashi, Samira Khaledi, Mohammad Houshyari, "CT Simulation to Evaluate of Pelvic Lymph Node Coverage in Conventional Radiotherapy Fields Based on Bone and Vessels Landmarks in Prostate Cancer Patients”, Iran J Cancer Prev. 2016 ; 9 (3): e6233.

[303] Amir Shahram Yousefi Kashi, Abolfazl Razzaghdoust, Afshin Rakhsha, "A Comparative Study of Treatment Toxicities Between FOLFOX 4 and Modified FOLFOX 6 in Iranian Colorectal Cancer Patients”, Iran J Cancer Prev. 2017; 10 (1): e9429.

[304] Amir Shahram Yousefi Kashi, Sharareh Yazdanfar, Mohammad-Esmaeil Akbari, Afshin Rakhsha, "Triple Negative Breast Cancer in Iranian Women: Clinical Profile and Survival Study”, Int J Cancer Manag. 2017; 10 (8): e10471.

[305] Amir Shahram Y. Kashi, Rezvan Montazeri, Afshin Rakhsha, "Clinical Outcome and Prognostic Factors in Iranian Breast Cancer Patients After Neoadjuvant Chemotherapy: A Comparative Matched Study”, Int J Cancer Manag. 2018; 11 (5): e67739.

[306] Afshin Rakhsha, Amir Anvari, Abolfazl Razzaghdoust, Amir Shahram Yousefi Kashi, “Clinical Outcome and Prognostic Factors for Very Young Patients with Breast Cancer: A Comparative Matched Single Institution Study in Iran”, Int J Cancer Manag. $2017 ; 10$ (9): e11772.

[307] Afshin Rakhsha, Amir Shahram Yousefi Kashi, Seied Mohsen Hoseini, "Evaluation of Survival and Treatment Toxicity with High-Dose-Rate Brachytherapy with Cobalt 60 In Carcinoma of Cervix”, Iran J Cancer Preven. 2015; 8 (4): e3573.

[308] A. Sh. Yousefi Kashi, B. Mofid, H. R. Mirzaei, P. Azadeh, 2010. "Overall Survival and Related Prognostic Factors in Metastatic Brain Tumors Treated with Whole Brain Radiation Therapy”, Research Journal of Medical Sciences, Volume: 4, Issue: 3, Page No.: $213-216$.

[309] A. Heidari, K. Schmitt, M. Henderson, E. Besana, "A Novel Prospect on Interaction of Synchrotron Radiation Emission and Europium Nanoparticles for Human Cancer Cells, Tissues and Tumors Treatment”, European Modern Studies Journal, 3 (5), 11-24, 2019.

[310] A. Heidari, K. Schmitt, M. Henderson, E. Besana, "Advantages, Effectiveness and Efficiency of Using Neodymium Nanoparticles by 3D Finite Element Method (FEM) as an Optothermal Human Cancer Cells, Tissues and Tumors Treatment under Synchrotron Radiation”, International Journal of Advanced Chemistry, 7 (2) 119-135, 2019.

[311] A. Heidari, K. Schmitt, M. Henderson, E. Besana, "Role and Applications of Promethium Nanoparticles in Human Cancer Cells, Tissues and Tumors Treatment”, Scientific Modelling and Research, 4 (1): 8-14, 2019. 
[312] A. Heidari, J. Esposito, A. Caissutti, "Maitotoxin Time-Resolved Absorption and Resonance FT-IR and Raman Biospectroscopy and Density Functional Theory (DFT) Investigation of Vibronic-Mode Coupling Structure in Vibrational Spectra Analysis: A Spectroscopic Study on an Anti-Cancer Drug”, Glob Imaging Insights 4 (2), 1-13, 2019.

[313] A. Heidari, J. Esposito, A. Caissutti, "Biotoxin Time-Resolved Absorption and Resonance FT-IR and Raman Biospectroscopy and Density Functional Theory (DFT) Investigation of Vibronic-Mode Coupling Structure in Vibrational Spectra Analysis”, Glob Imaging Insights 4 (2), 1-14, 2019.

[314] A. Heidari, J. Esposito, A. Caissutti, "Time-Resolved Resonance FT-IR and Raman Spectroscopy and Density Functional Theory Investigation of Vibronic-Mode Coupling Structure in Vibrational Spectra of Nanopolypeptide Macromolecule beyond the Multi-Dimensional Franck-Condon Integrals Approximation and Density Matrix Method", Glob Imaging Insights 4 (2), 1-14, 2019.

[315] A. Heidari, J. Esposito, A. Caissutti, "Cholera Toxin Time-Resolved Absorption and Resonance FT-IR and Raman Biospectroscopy and Density Functional Theory (DFT) Investigation of Vibronic-Mode Coupling Structure in Vibrational Spectra Analysis”, Glob Imaging Insights 4 (2), 1-14, 2019.

[316] A. Heidari, J. Esposito, A. Caissutti, "Nodularin Time-Resolved Absorption and Resonance FT-IR and Raman Biospectroscopy and Density Functional Theory (DFT) Investigation of Vibronic-Mode Coupling Structure in Vibrational Spectra Analysis”, Glob Imaging Insights 4 (2), 1-14, 2019.

[317] A. Heidari, J. Esposito, A. Caissutti, "Cangitoxin Time-Resolved Absorption and Resonance FT-IR and Raman Biospectroscopy and Density Functional Theory (DFT) Investigation of Vibronic-Mode Coupling Structure in Vibrational Spectra Analysis”, Glob Imaging Insights 4 (2), 1-13, 2019.

[318] A. Heidari, J. Esposito, A. Caissutti, “Ciguatoxin Time-Resolved Absorption and Resonance FT-IR and Raman Biospectroscopy and Density Functional Theory (DFT) Investigation of Vibronic-Mode Coupling Structure in Vibrational Spectra Analysis”, Glob Imaging Insights 4 (2), 1-14, 2019.

[319] A. Heidari, J. Esposito, A. Caissutti, "Brevetoxin (a) and (b) Time-Resolved Absorption and Resonance FT-IR and Raman Biospectroscopy and Density Functional Theory (DFT) Investigation of Vibronic-Mode Coupling Structure in Vibrational Spectra Analysis: A Spectroscopic Study on an Anti-HIV Drug”, Cientific Drug Delivery Research 1 (2), 11-16, 2019.

[320] A. Heidari, J. Esposito, A. Caissutti, "Cobrotoxin Time-Resolved Absorption and Resonance FT-IR and Raman Biospectroscopy and Density Functional Theory (DFT) Investigation of Vibronic-Mode Coupling Structure in Vibrational Spectra Analysis”, Trends in Res 3 (1), 1-13, 2019.

[321] A. Heidari, J. Esposito, A. Caissutti, "Cylindrospermopsin Time-Resolved Absorption and Resonance FT-IR and Raman Biospectroscopy and Density Functional Theory (DFT) Investigation of Vibronic-Mode Coupling Structure in Vibrational Spectra Analysis”, Trends in Res 3 (1), 1-14, 2019.

[322] A. Heidari, J. Esposito, A. Caissutti, “Anthrax Toxin Time-Resolved Absorption and Resonance FT-IR and Raman Biospectroscopy and Density Functional Theory (DFT) Investigation of Vibronic-Mode Coupling Structure in Vibrational Spectra Analysis”, Trends in Res 3 (1), 1-14, 2019.

[323] A. Heidari, K. Schmitt, M. Henderson, E. Besana, "Investigation of Moscovium Nanoparticles as Anti-Cancer Nano Drugs for Human Cancer Cells, Tissues and Tumors Treatment”, Elixir Appl. Chem. 137A, 53943-53963, 2019.

[324] A. Heidari, K. Schmitt, M. Henderson, E. Besana, "Study of Function of the Beam Energy and Holmium Nanoparticles Using 3D Finite Element Method (FEM) as an Optothermal Human Cancer Cells, Tissues and Tumors Treatment”, European Journal of Advances in Engineering and Technology, 6 (12): 34-62, 2019.

[325] A. Heidari, K. Schmitt, M. Henderson, E. Besana, “Human Cancer Cells, Tissues and Tumors Treatment Using Dysprosium Nanoparticles”, Asian J. Mat. Chem. 4 (3-4), pp. 47-51, 2019.

[326] A. Heidari, K. Schmitt, M. Henderson, E. Besana, "Simulation of Interaction of Synchrotron Radiation Emission as a Function of the Beam Energy and Plutonium Nanoparticles Using 3D Finite Element Method (FEM) as an Optothermal Human Cancer Cells, Tissues and Tumors Treatment”, J. Cancer Research and Cellular Therapeutics, Volume 2 (4), Pages 1-19, 2019.

[327] A. Heidari, K. Schmitt, M. Henderson, E. Besana, "Study of Gadolinium Nanoparticles Delivery Effect on Human Cancer Cells, Tissues and Tumors Treatment under Synchrotron Radiation”, Applied Chemistry, 2 (2) 55-97, 2019.

[328] A. Heidari, K. Schmitt, M. Henderson, E. Besana, R. Gobato, "Pros and Cons of Livermorium Nanoparticles for Human Cancer Cells, Tissues and Tumors Treatment under Synchrotron Radiation Using Mathematica 12.0”, Parana Journal of Science and Education (PJSE) - v. 6, n. 1, (1-31) January $11,2020$.

[329] R. Gobato, M. R. R. Gobato, A. Heidari, A. Mitra, “Challenging Giants. Hartree- Fock Methods Analysis Protonated Rhodochrosite Crystal and Potential in the Elimination of Cancer Cells Through Synchrotron Radiation”, Biomed J Sci \& Tech Res 25 (1), pp. 18843-18848, 2020.

[330] A. Heidari, K. Schmitt, M. Henderson, E. Besana, "Simulation of Interaction between Ytterbium Nanoparticles and Human Gum Cancer Cells, Tissues and Tumors Treatment under Synchrotron Radiation”, Dent Oral Maxillofac Res, Volume 5, Issue 5, Pages 1-18, 2019.

[331] A. Heidari, K. Schmitt, M. Henderson, E. Besana, "Modelling of Interaction between Curium Nanoparticles and Human Gum Cancer Cells, Tissues and Tumors Treatment under Synchrotron Radiation”, Dent Oral Maxillofac Res, Volume 5, Issue 5, Pages 1-18, 2019.

[332] A. Heidari, K. Schmitt, M. Henderson, E. Besana, "Study of Berkelium Nanoparticles Delivery Effectiveness and Efficiency on Human Gum Cancer Cells, Tissues and Tumors Treatment under Synchrotron Radiation”, Dent Oral Maxillofac Res, Volume 5, Issue 5, Pages 1-18, 2019.

[333] A. Heidari, K. Schmitt, M. Henderson, E. Besana, "Fermium Nanoparticles Delivery Mechanism in Human Gum Cancer Cells, Tissues and Tumors Treatment under Synchrotron Radiation”, Dent Oral Maxillofac Res, Volume 5, Issue 5, Pages 1-17, 2019.

[334] A. Heidari, K. Schmitt, M. Henderson, E. Besana, “Advantages of Lawrencium Nanoparticles for Human Gum Cancer Cells, Tissues and Tumors Treatment under Synchrotron Radiation”, Dent Oral Maxillofac Res, Volume 5, Issue 5, Pages 1-18, 2019.

[335] A. Heidari, K. Schmitt, M. Henderson, E. Besana, "Pros and Cons of the Roentgenium Nanoparticles for Human Gum Cancer Cells, Tissues and Tumors Treatment under Synchrotron Radiation”, Dent Oral Maxillofac Res, Volume 5, Issue 5, Pages 1-17, 2019.

[336] A. Heidari, K. Schmitt, M. Henderson, E. Besana, "Imagery of Flerovium Nanoparticles Delivery Process in Human Gum Cancer Cells, Tissues and Tumors Treatment under Synchrotron Radiation”, Dent Oral Maxillofac Res, Volume 5, Issue 5, Pages 1-18, 2019.

[337] A. Heidari, J. Esposito, A. Caissutti, "Maitotoxin Time-Resolved Absorption and Resonance FT-IR and Raman Biospectroscopy and Density Functional Theory (DFT) Investigation of Vibronic-Mode Coupling Structure in Vibrational Spectra Analysis: A Spectroscopic Study on an Anti-Gum Cancer Drug”, Dent Oral Maxillofac Res, Volume 5, Issue 5, Pages 1-16, 2019.

[338] A. Heidari, J. Esposito, A. Caissutti, "Batrachotoxin Time-Resolved Absorption and Resonance FT-IR and Raman Biospectroscopy and Density Functional Theory (DFT) Investigation of Vibronic-Mode Coupling Structure in Vibrational Spectra Analysis: A Spectroscopic Study on an AntiGum Cancer Drug”, Dent Oral Maxillofac Res, Volume 5, Issue 6, Pages 1-16, 2019.

[339] A. Heidari, K. Schmitt, M. Henderson, E. Besana, "Hafnium Nanoparticles and Their Roles and Applications in Human Gum Cancer Cells, Tissues and Tumors Treatment under Synchrotron Radiation”, Dent Oral Maxillofac Res, Volume 5, Issue 6, Pages 1-17, 2019.

[340] A. Heidari, K. Schmitt, M. Henderson, E. Besana, "Dramaturgy of Technetium Nanoparticles Delivery Process in Human Gum Cancer Cells, Tissues and Tumors Treatment under Synchrotron Radiation”, Dent Oral Maxillofac Res, Volume 5, Issue 6, Pages 1-19, 2019.

[341] A. Heidari, K. Schmitt, M. Henderson, E. Besana, "Computational Approach to Interaction between Synchrotron Radiation Emission as a Function of the Beam Energy and Ruthenium Nanoparticles in Human Gum Cancer Cells, Tissues and Tumors Treatment”, Dent Oral Maxillofac Res, Volume 5, Issue 6, Pages 1-18, 2019.

[342] A. Heidari, K. Schmitt, M. Henderson, E. Besana, “Appearance Check of Rhodium Nanoparticles Delivery Trend in Human Gum Cancer Cells, Tissues and Tumors Treatment under Synchrotron Radiation”, Dent Oral Maxillofac Res, Volume 5, Issue 6, Pages 1-19, 2019.

[343] A. Heidari, K. Schmitt, M. Henderson, E. Besana, “Orientation Rhenium Nanoparticles Delivery Target on Human Gum Cancer Cells, Tissues and Tumors under Synchrotron Radiation”, Dent Oral Maxillofac Res, Volume 5, Issue 6, Pages 1-18, 2019.

[344] A. Heidari, K. Schmitt, M. Henderson, E. Besana, "Drug Delivery Systems (DDSs) of Osmium Nanoparticles on Human Gum Cancer Cells, Tissues and Tumors Treatment under Synchrotron Radiation”, Dent Oral Maxillofac Res, Volume 5, Issue 6, Pages 1- $18,2019$.

[345] A. Heidari, K. Schmitt, M. Henderson, E. Besana, "Development of Successful Formulations for Oral Drug Delivery Concepts of Iridium Nanoparticles in Human Gum Cancer Cells, Tissues and Tumors Treatment under Synchrotron Radiation”, Dent Oral Maxillofac Res, Volume 5, Issue 6, Pages 1-19, 2019. 
[346] A. Heidari, K. Schmitt, M. Henderson, E. Besana, “Classification of Drug Delivery System of Niobium Nanoparticles in Human Gum Cancer Gum Cells, Tissues and Tumors Treatment under Synchrotron Radiation”, Dent Oral Maxillofac Res, Volume 6, Issue 1, Pages 1-17, 2020.

[347] A. Heidari, K. Schmitt, M. Henderson, E. Besana, "Types of Drug Delivery System Slideshare of Protactinium Nanoparticles in Human Gum Cancer Cells, Tissues and Tumors Treatment under Synchrotron Radiation”, Dent Oral Maxillofac Res, Volume 6, Issue 1, Pages 1-17, 2020.

[348] A. Heidari, K. Schmitt, M. Henderson, E. Besana, "New Drug Delivery System in Pharmaceutics of Neptunium Nanoparticles in Human Gum Cancer Cells, Tissues and Tumors Treatment under Synchrotron Radiation”, Dent Oral Maxillofac Res, Volume 6, Issue 1, Pages 1-18, 2020.

[349] A. Heidari, K. Schmitt, M. Henderson, E. Besana, “Drug Delivery Describes the Method and Approach to Delivering Drugs or Pharmaceuticals and Other Xenobiotics to Their Site of Action within Radon Nanoparticles Effects on Human Gum Cancer Cells, Tissues and Tumors Treatment under Synchrotron Radiation”, Dent Oral Maxillofac Res, Volume 6, Issue 1, Pages 1-18, 2020.

[350] A. Heidari, K. Schmitt, M. Henderson, E. Besana, "Applications of Oganesson Nanoparticles in Increasing Rapidly with the Promise of Targeted and Efficient Drug Delivery in Human Gum Cancer Cells, Tissues and Tumors Treatment under Synchrotron Radiation”, Dent Oral Maxillofac Res, Volume 6, Issue 1, Pages 1-19, 2020.

[351] A. Heidari, K. Schmitt, M. Henderson, E. Besana, "Wheeler-Feynman Time-Symmetric Study of Effectiveness and Efficiency of Terbium Nanoparticles Delivery Mechanism in Human Cancer Cells, Tissues and Tumors under Synchrotron Radiation”, Frontiers Drug Chemistry Clinical Res, Volume 3, Issue 1, Pages 1-13, 2020.

[352] A. Heidari, K. Schmitt, M. Henderson, E. Besana, "Simulation of Interaction of Synchrotron Radiation Emission as a Function of the Beam Energy and Californium Nanoparticles Using 3D Finite Element Method (FEM) as an Optothermal Human Cancer Cells, Tissues and Tumors Treatment", Oncol Res: Open Acce. 1 (1): 1-17, 2019.

[353] A. Heidari, “Market Analysis of Glycobiology and Glycochemistry 2020”, J Genet Disor Genet Rep. 8: 1, 2019.

[354] A. Heidari, K. Schmitt, M. Henderson, E. Besana, "Synchrotron Radiation Emission as a Function of the Beam Energy and Thorium Nanoparticles", International Medicine; 2 (1): 67-73, 2020

[355] A. Heidari, K. Schmitt, M. Henderson, E. Besana, "Stochastic Study of Relativistic Lutetium Nanoparticles Moving in a Quantum Field of Synchrotron Radiation Emission When Charged Lutetium Nanoparticles Are Accelerated Radially in Human Cancer Cells, Tissues and Tumors Treatment", Frontiers Drug Chemistry Clinical Res, Volume 3, Issue 1, Pages 1-15, 2020.

[356] A. Heidari, A. Caissutti, M. Henderson, K. Schmitt, E. Besana, J. Esposito, V. Peterson, "Recent New Results and Achievements of California South University (CSU) BioSpectroscopy Core Research Laboratory for COVID-19 or 2019-nCoV Treatment: Diagnosis and Treatment Methodologies of "Coronavirus", Journal of Current Viruses and Treatment Methodologies, Vol-1, Issue 1, Pg. no. 3-41, 2020.

[357] A. Heidari, K. Schmitt, M. Henderson, E. Besana, "Study of Human Cancer Cells, Tissues and Tumors Treatment Through Interaction Between Synchrotron Radiation and Cerium Nanoparticles", Sci Lett. 8 (1): 7-17, 2020

[358] A. Heidari, K. Schmitt, M. Henderson, E. Besana, "Study of Characteristic Polarization and the Frequencies Generated in Interaction of Synchrotron Radiation Emission and Actinium Nanoparticles in Human Cancer Cells, Tissues and Tumors Treatment Process", Parana Journal of Science and Education (PJSE)-v. 6, n.3, (13-47) April 15, 2020

[359] A. Heidari, K. Schmitt, M. Henderson, E. Besana, "Californium Nanoparticles and Human Cancer Treatment: Commemorating the 100 th (1920 2020) Anniversary of the California South University (CSU)”, Parana Journal of Science and Education (PJSE)-v. 6, n. 3, (48-83) April 15, 2020.

[360] R. Gobato, M. R. R. Gobato, A. Heidari, A. Mitra, I. K. K. Dosh, "Secret Messages in Enigmatic Playful Texts", ABEB. 4 (2): Pages 1-10, 2020.

[361] A. Heidari, K. Schmitt, M. Henderson, E. Besana, “A Chemical Review on Cancer Immunology and Immunodeficiency", International Journal of Advanced Chemistry, Vol. 8, No. 1, Pages 27-43, 2020

[362] A. Heidari, V. Peterson, "A Comprehensive Review on Functional Roles of Cancerous Immunoglobulins and Potential Applications in Cancer Immunodiagnostics and Immunotherapy”, International Journal of Advanced Chemistry, Vol. 8, No. 1, Pages 44-58, 2020.

[363] A. Heidari, V. Peterson, "An Encyclopedic Review on Stereotactic Hypofractionated Radiotherapy, Re-Irradiation and Cancer Genome Research", International Journal of Advanced Chemistry, Vol. 8, No. 1, Pages 59-74, 2020.

[364] A. Heidari, V. Peterson, “A Pervasive Review on Biomarker in Cervical Intraepithelial Lesions and Carcinoma”, International Journal of Advanced Chemistry, Vol. 8, No. 1, Pages 75-88, 2020

[365] A. Heidari, "Future Advanced Study of Thin Layers of DNA/RNA Hybrid Molecule Nanostructure”, J Mol Nanot Nanom 2 (1): $110,2020$.

[366] Amir Shahram Yousefi Kashi, Samira Khaledi, Mohammad Houshyari, "CT Simulation to Evaluate of Pelvic Lymph Node Coverage in Conventional Radiotherapy Fields Based on Bone and Vessels Landmarks in Prostate Cancer Patients”, Iran J Cancer Prev. 2016; 9 (3): e6233.

[367] Amir Shahram Yousefi Kashi, Abolfazl Razzaghdoust, Afshin Rakhsha, "A Comparative Study of Treatment Toxicities Between FOLFOX 4 and Modified FOLFOX 6 in Iranian Colorectal Cancer Patients”, Iran J Cancer Prev. 2017; 10 (1): e9429.

[368] Amir Shahram Yousefi Kashi, Sharareh Yazdanfar, Mohammad-Esmaeil Akbari, Afshin Rakhsha, "Triple Negative Breast Cancer in Iranian Women: Clinical Profile and Survival Study”, Int J Cancer Manag. 2017; 10 (8): e10471.

[369] Amir Shahram Y. Kashi, Rezvan Montazeri, Afshin Rakhsha, "Clinical Outcome and Prognostic Factors in Iranian Breast Cancer Patients After Neoadjuvant Chemotherapy: A Comparative Matched Study”, Int J Cancer Manag. 2018; 11 (5): e67739.

[370] Afshin Rakhsha, Amir Anvari, Abolfazl Razzaghdoust, Amir Shahram Yousefi Kashi, "Clinical Outcome and Prognostic Factors for Very Young Patients with Breast Cancer: A Comparative Matched Single Institution Study in Iran”, Int J Cancer Manag. $2017 ; 10$ (9): e11772.

[371] Afshin Rakhsha, Amir Shahram Yousefi Kashi, Seied Mohsen Hoseini, "Evaluation of Survival and Treatment Toxicity with High-Dose-Rate Brachytherapy with Cobalt 60 In Carcinoma of Cervix”, Iran J Cancer Preven. 2015; 8 (4): e3573. 20

[372] A. Sh. Yousefi Kashi, B. Mofid, H. R. Mirzaei, P. Azadeh, 2010. “Overall Survival and Related Prognostic Factors in Metastatic Brain Tumors Treated with Whole Brain Radiation Therapy”, Research Journal of Medical Sciences, Volume: 4, Issue: 3, Page No.: $213-216$. 